\title{
الأسباب الاجتماعية لصناعة الإرهاب الجديد
}

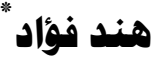

أدت العولمة إلى تحولات جذرية فى العالم استفاد الإرهاب من بعضها، وأسهم بعضها الآخر

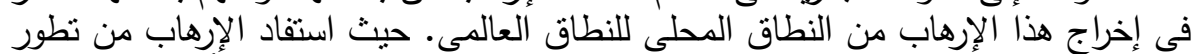

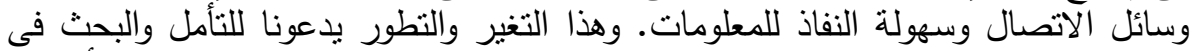

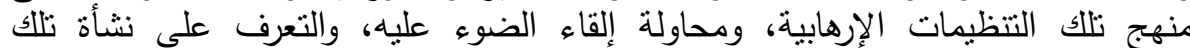

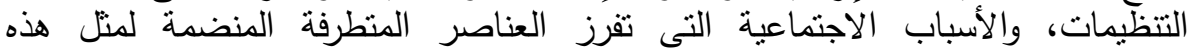

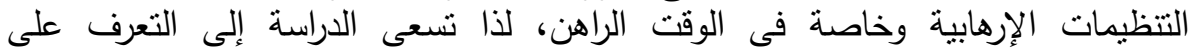

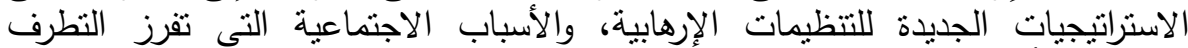
والإرهاب، وأهم الآليات المطروحة لمواجهته.

برزت العولمة كنتيجة للتحولات فى وسائل الاتصالات وسهولة نفاذ المعلومات عبر شبكة الإنترنت فى الآونة الأخيرة، الأمر الذى أدى إلى تحول العالم لقربة صغيرة متصلة ببعضها، فالعولمة أدت إلى تحولات جذرية فى العالم استفاد الإرهاب من بعضها، وأسهم بعضها الآخر فى إخراج هذا الإرهاب من النطاق المحلى للنطاق العالمى. وهذا ما برز فى الوقت الراهن، حيث أدت العولمة إلى إنى حدوث تحولات من أهمها تطور وسائل الاتصال التى أدت إلى سهولة نفاذ المعلومات، والتى حدت مـن قـوة الدولـة، وقدمت مزبدًا من الأدوات المعلوماتيـة للجماعات الإرهابية، ودعمت الثبكات التى يعمل من خلالها الإرهابيون. ومن ناحيـة أخـرى، أدى انفتاح الدول أمـام مزيد مـن التعاملات المالبية والتجـارية * هند فؤاد، خبير، قسم بحوث وقياسات الرأى العام، المركز القومى للبحوث الاجتماعية والجنائية. الدجلة الجنائية القومية، المجلد الواحد والستون، العدد الثانس، يوليو 11 . r. 
السهلة إلى تيسير عمليات تمويل الإرهاب. كما وفرت العولمة مناخًا مواتيًا

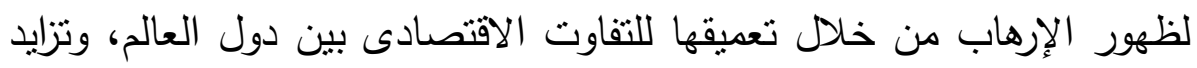

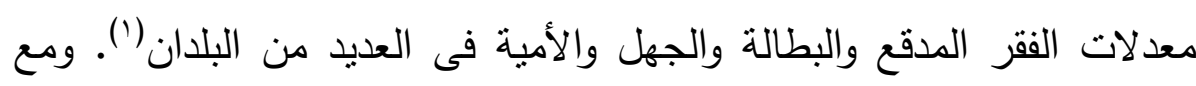

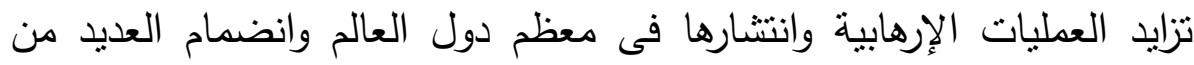
الفئات من الطبقات المختلفة إلى صفوف تلك التنظيمات، نظرًا لامتلاكها وسائل التكنولوجيا الحديثة، الأمر الذى خلق بيئة مهيئة لظهور الإرهاب وانتناره.

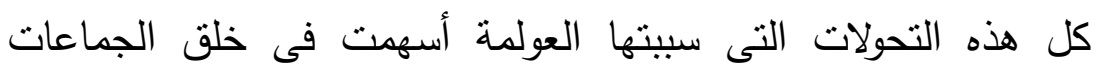

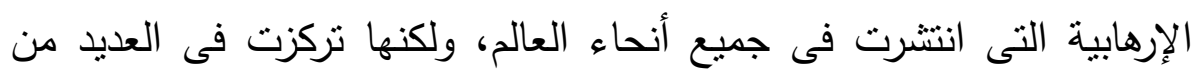
دول الثرق الأوسط وجنوب شرق آسيا. وهذه الجماعات الإرهابية لها العديد

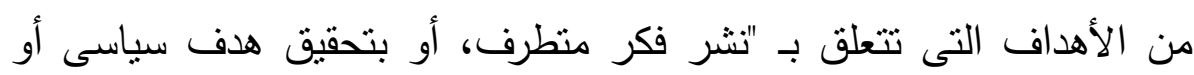

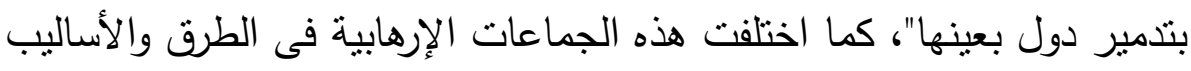

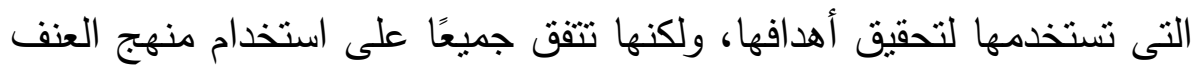
بشتى صوره لتحقيق ما ترنو إليه. ولم تعد ظاهرة الإرهاب ظاهرة محلية، بل أصبحت ظاهرة إله عابرة للحدود،

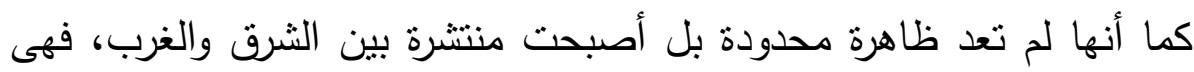
أصبحت صناعة تنتخدمها أو تمولها بعض الدول فى الفترة الأخيرة لتحقيق أهداف بعينها. فيعد تتظيم داعش الإرهابى من أخطر تلك التظظيمات العابرة للحدود، حيث اخترق هذا التنظيم العديد من الدول، واستقر داخل دولتى العراق

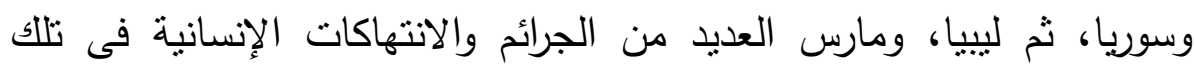
البلاد، حيث مارس العنف بشتى صوره، والتدمير المتعدد للمبانى والآثار والمنشآت المهمة، هذا بخلاف نشر صور القتل والتمثيل بالجثث والأسر والثر

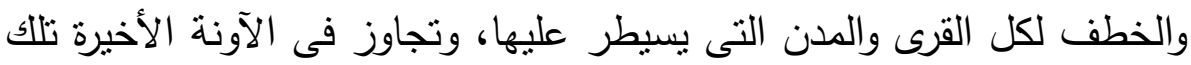


الانتهاكات والجرائم إلى تجنيد الأطفال والنساء واستخلالهم فى ممارسة العمليات التفجيرية والإرهابية.

ومارست بعض التنظيمات الإرهابية مثل "تتظيم داعش، وجماعة بيت

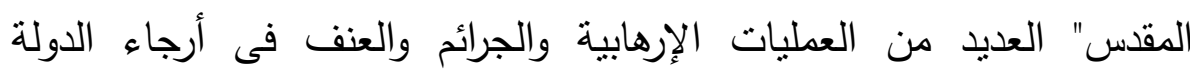
المصرية، والتى عادة ما يتزامن حدوثها بشكل كبير مع الأحداث المهمة التى التى التهابه

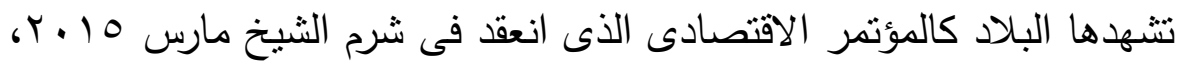

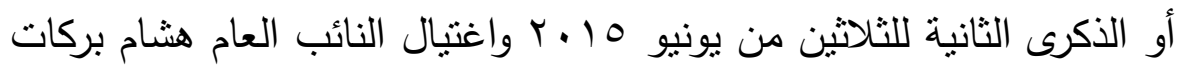

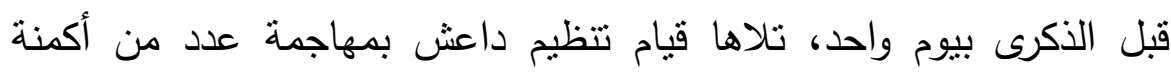
الثرطة فى سيناء واستهداف الضباط والجنود الكثير من المرات، ثم تفجير

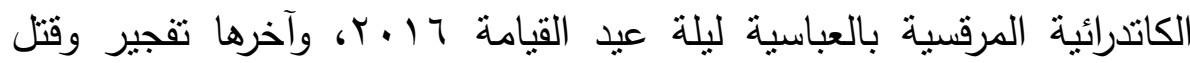

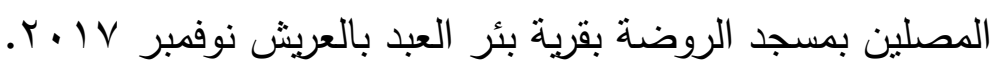

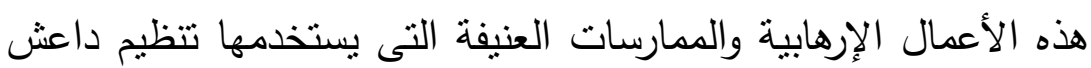
تجاه الدولة المصرية لا تتم من فراغ؛ وإنما ورائها الكثير من الأسباب، فمنها

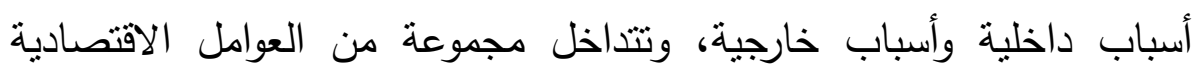
والاجتماعية والنقافية مشكلة جملة من الأسباب الداخلية والتى سنذكرها

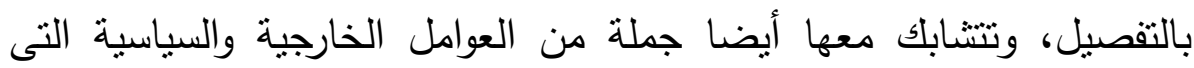
تحيط بوطننا العزيز لتتكل الأسباب الخارجية، فظروف المنطقة العربية الراهنة

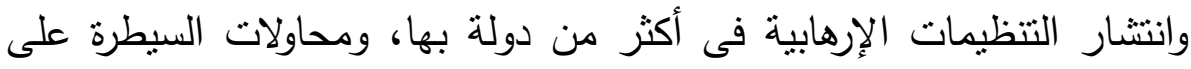

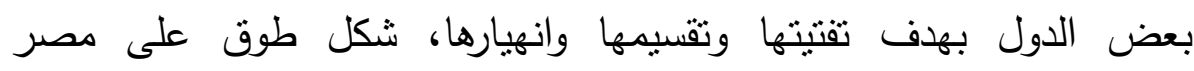
يحاصرها من العديد من الجهات الثمالية والغربية والجنوبية، فنلك المخططات

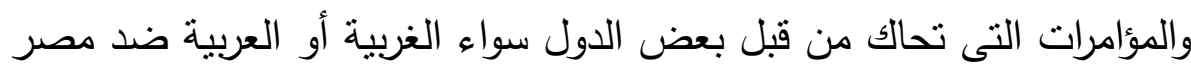
تهدف لتفنتيت القوة الاقتصادية للاولة وإضعاف مكانتها السياسية. 
وفى سياق متابعة الحوادث والعمليات الإرهابية وتكرارها، وتطورها فى

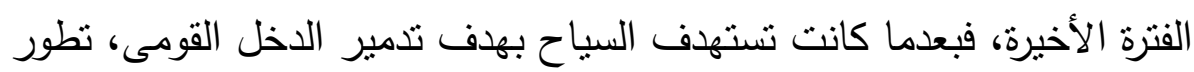
الأمر وأصبحت نستهدف المؤسسات والمنشآت الحكومية، ثم القوات المسلحة بهنة والثرطة، والقضاة، ثم استهدفت الأقباط، وأخيرا المسلمين فى عملية تفجير مسجد الروضة بمنطقة بئر العبد بشمال سيناء، فتلك التنظيمات الإرهابية

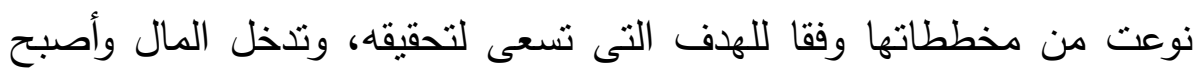
الإرهاب صناعة وليس هدفًا لإنشاء دولة إسلامية أو نشر فكر دينى وغيرها من الادعاءات المزيفة التى باتت واضحة للعيان.

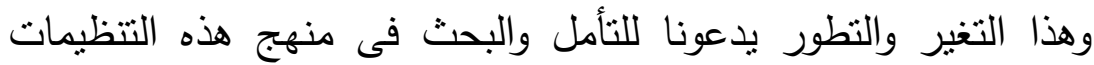

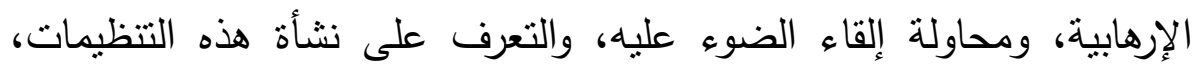
والأسباب الاجتماعية التى تفرز العناصر المنطرفة المنضمة لمثل هذه الهنه التنظيمات الإرهابية وخاصة فى الوقت الراهن.

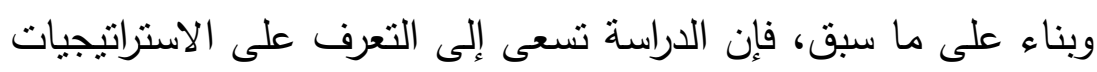

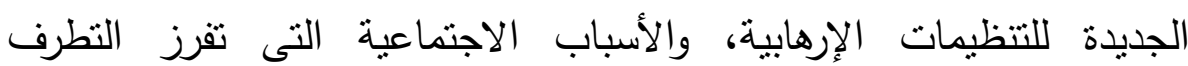

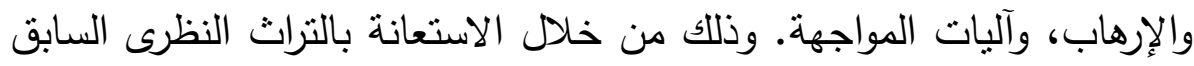
فى مجال الإرهاب، ومناقثة وتحليل الفرضيات والعلاقات الخاصة بتأصيل أسباب التطرف والإرهاب وتطبيقه على الواقع المصرى. فهناك اختلاف كبير

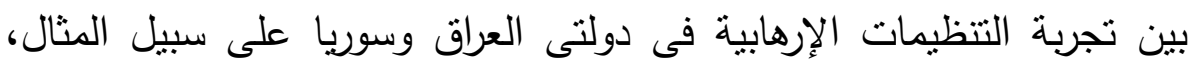
وبين تجربة هذه التتظيمات فى مصر ، فلكل مجتمع ظروف ناريخية واجتماعية

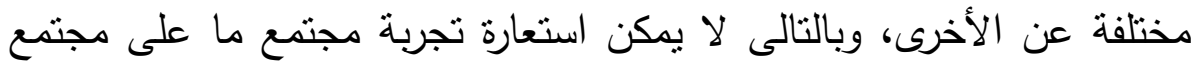

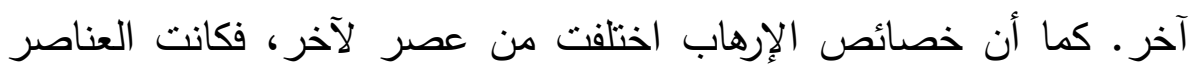
المتطرفة تتسم بخصائص منل العنف واستخدام القوة وارتكاب الأعمال الوحشية 
وترويع الآمنين وغيرها من الأفعال الإجرامية، لكن فى العصر الحالى اختلفت

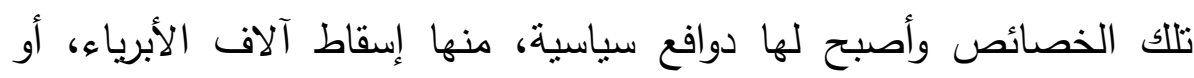

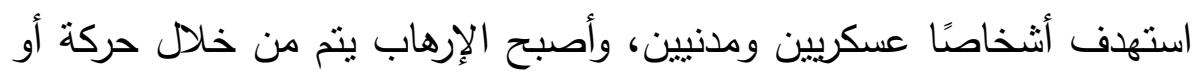

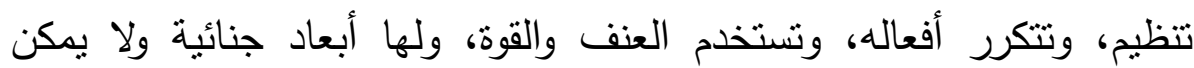

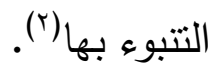

وتركز الدراسة على تحليل مجموعة الأسباب الداخلية الخاصة بمجتمعنا

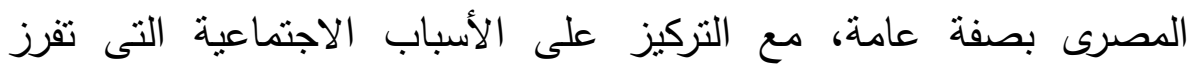

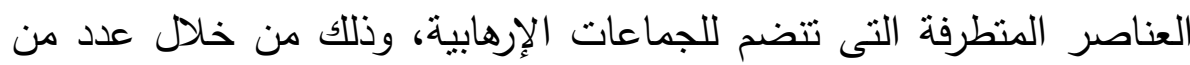

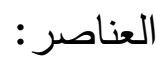
أولا: الإرهاب بين الفقر والتعليم والبطالة. ثانيا: البيئة الاجتماعية والثقافية السائدة والإرهاب. ثنالثا: الإرهاب بين الدين واللادين. رابعا: الإرهاب بين المجتمع الواقعى والافتراضى. لإنى لإنى خامسا: آليات مواجهة الإرهاب الجديد.

\section{أولا: الإرهاب بين الفقر والتعليم والبطالة} أثثر الكثير من الجدل حول علاقة الإرهاب بالفقر والبطالة والتعليم، وهى من

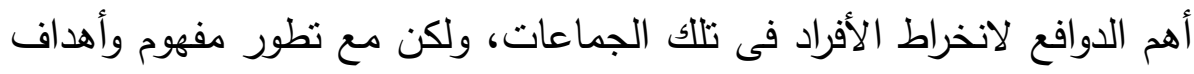

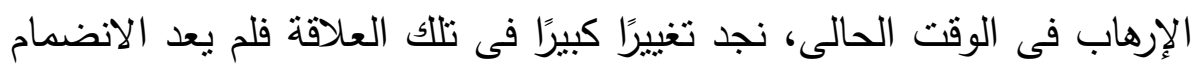

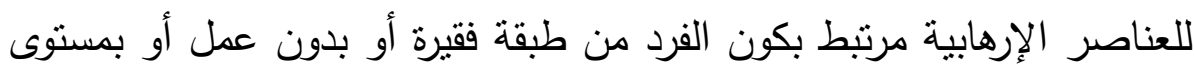
تعليمى منخفض، فهناك عناصر كثيرة فى تللك التنظيمات من الفئات المتعلمة والميسورة الحال ماديا، ويعملون فى مناصب ومهن مهمة. 
ويمكن القول بإن مجال البحث فى موضوع العلاقة بين الوضع الاقتصادى والعنف شهر انقساما حادا، فى مجرى التيار الرئيسى له، إلى

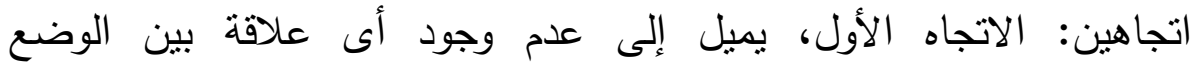

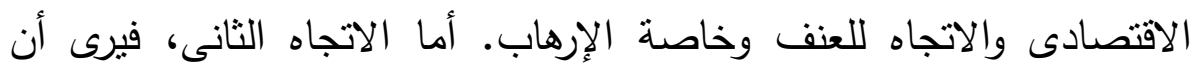

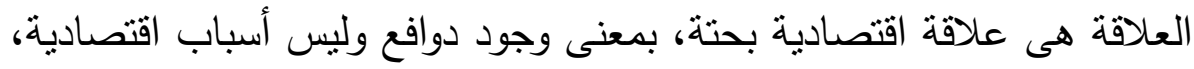

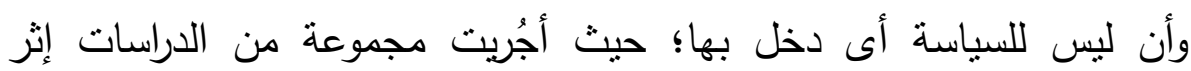

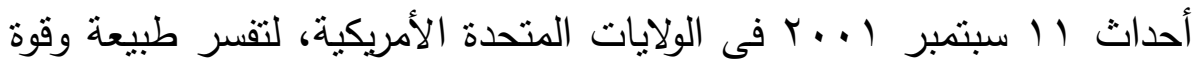
الارتباط بين الفقر وانخفاض المستوى التعليمى من جهة، والميل لاستخدام العنف واللجوء إلى العمل الإرهابى من جهة أخرى، ومن أهم هذه الدراسات

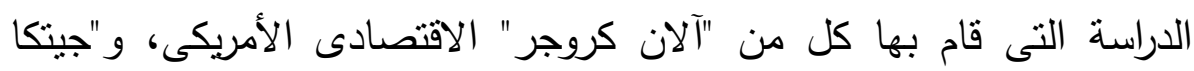

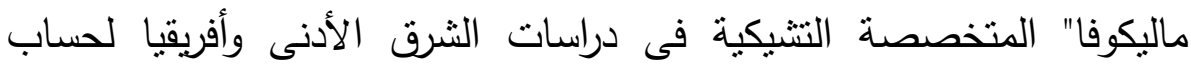
المجلس الوطنى للبحوث الاقتصادية فى الولايات المتحدة الأمريكية فى عام

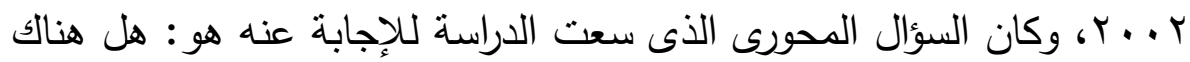

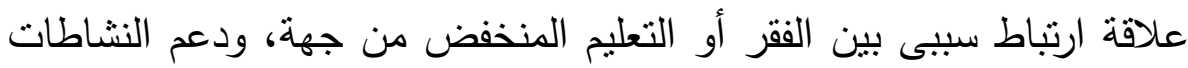

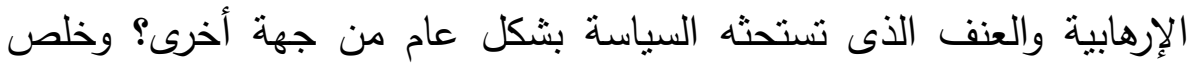

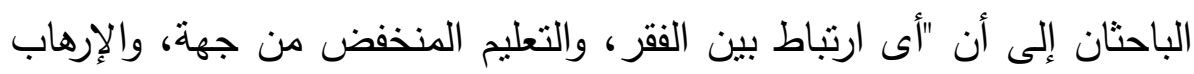

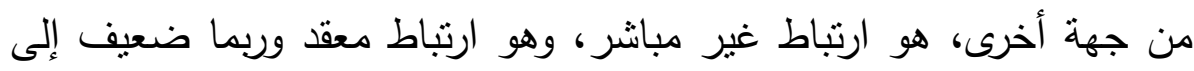

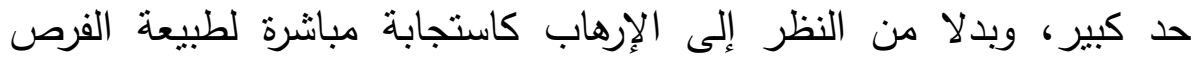

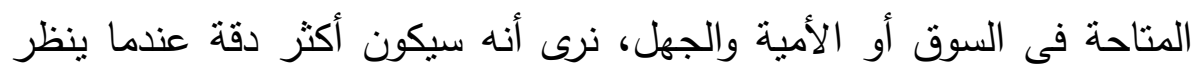

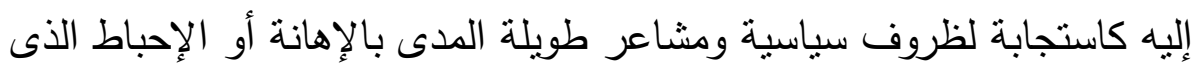

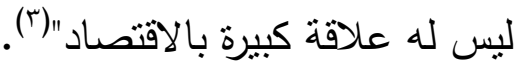


فى المقابل، كانت هناك نظرة "|قتصادية" تستتد إلى نظرية الاختيار

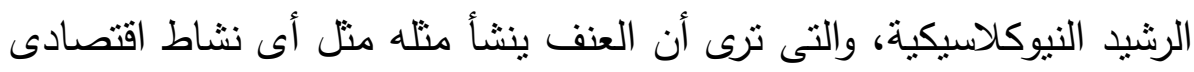

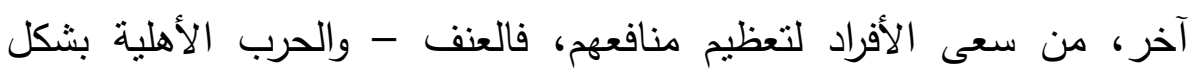

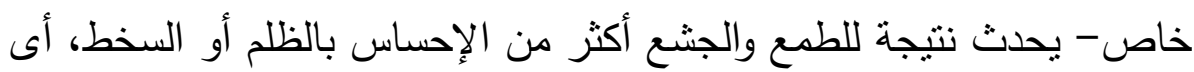

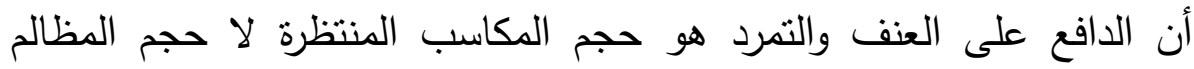
الواقعة على الأفراد والجماعات بالفعل، ووفقا لهذه النظرة، فإنه حيثما تزيد فرص تحقيق الربح على التكلفة المرتبطة بالعنف والتمرد (ارتفاع نفقة الفرصة

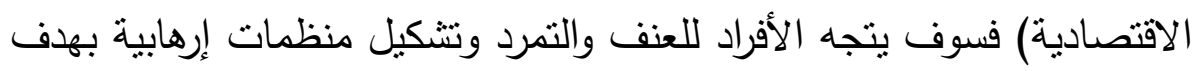

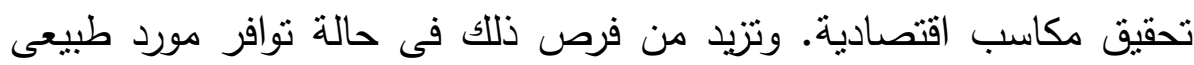

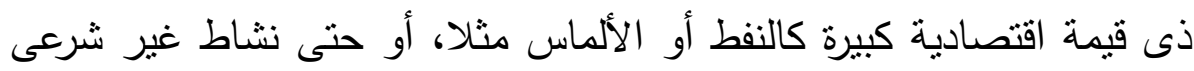
مرتفع الربحية كتجارة الأسلحة وتهريبها (ُ). وبالرغم من تسّيد نظرية الجذور الاجتماعية والاقتصادية لدراسات

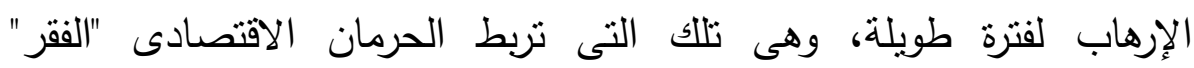
والإقصاء، أو التهميش الاجتماعى من ناحية والقيام بعطليات إرهابية من ناحية

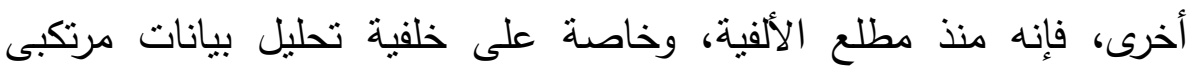

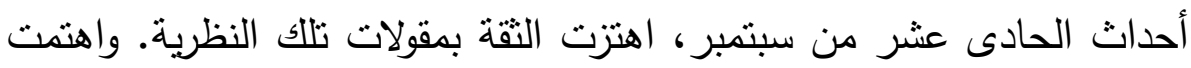

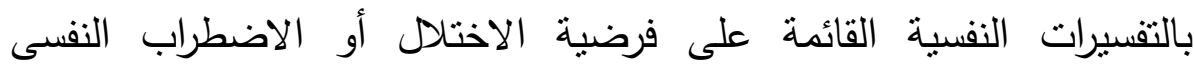

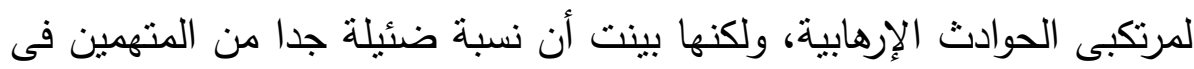

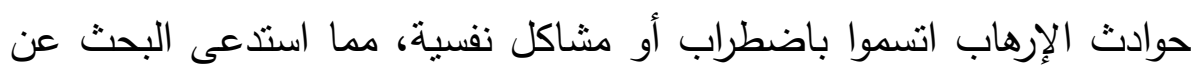

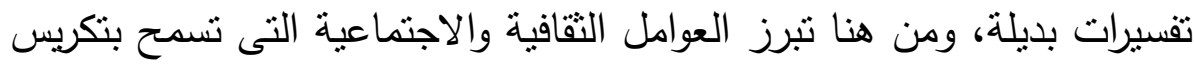

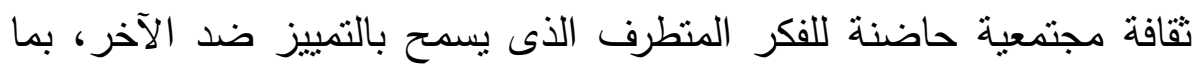


يمثل البنية التحتية للسلوك الذى قد يستخدم العنف فى ظل توافر الفرصة لذلك،

هذا فضلا عن دور صناعة السلاح فى دعم ثقافة العنف لتعزيز مكاسبها (ه). وبالتالى فالإرهاب متطور وديناميكى ولم يعد بالأثكال أو الأفعال

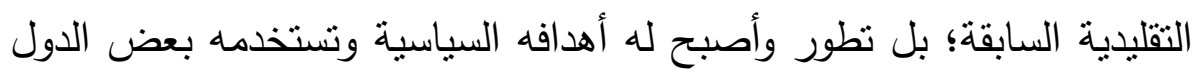

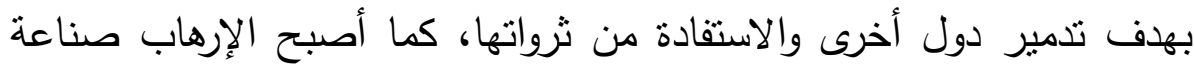

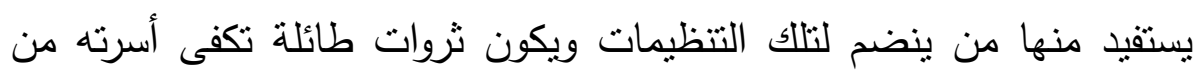

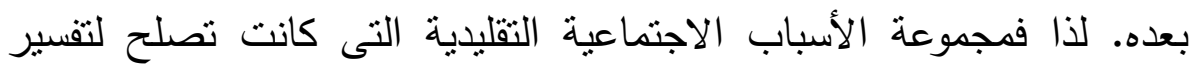

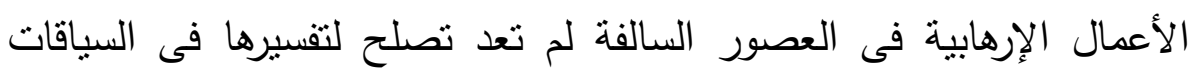

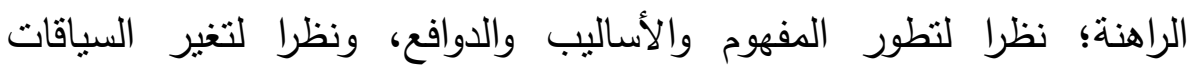
الاجتماعية التى تحدث فى إطارها، ومن ثم فلم تعد هناك علاقة ارتباطية بين الإرهاب وبين الفقر أو البطالة، بل أصبح الإرهاب والتنظيمات الإرهابية سبيًا

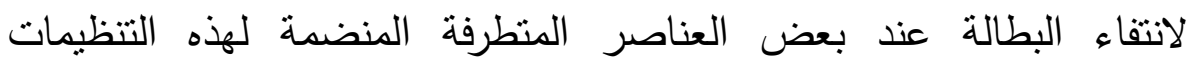

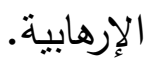

وبناء على ما سبق، يمكننا القول إن النظرة الاقتصادية منقسمة حول

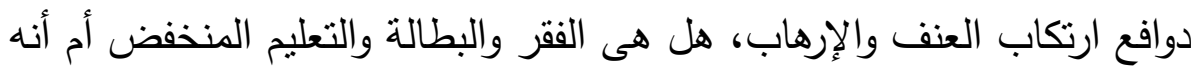
نشاط اقتصادى يستفيد منه المنمردون لتحقيق ثروات ضخمة وأهن الهداف سياسية؟ ولكن فى ظل ظروف المجتمع المصرى، وخصائصه الاجتماعية والاقتصادية

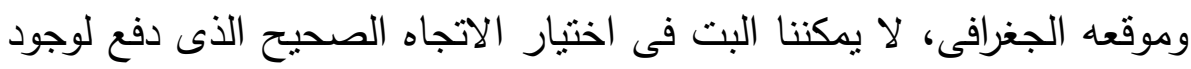

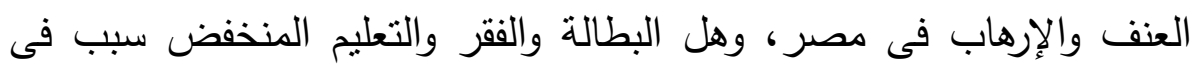
وجود الإرهاب أم لا؟ ولكن هناك العديد من الدوافع الاقتصادية والاجتماعية والسياسية والجغرافية المتداخلة والمنتابكة التى تفرز هذا الإرهاب. فلا يمكننا 
الفصل بين تلك الدوافع وأيهم الأساس فى وجود ذلك العنف، نظرا لخصوصية المجتمع المصرى وظروفه التاريخية والجغرافية والسياسية.

\section{ثانيا: البيئة الاجتماعية والثقافية السائدة والإرهاب}

تفرز البيئة الاجتماعية والثقافية السائدة فى المجتمع المصرى العديد من

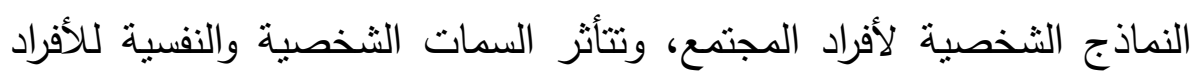

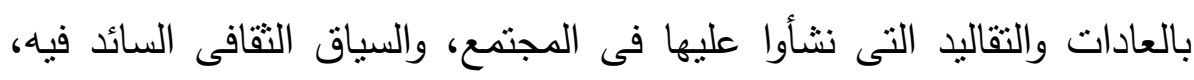

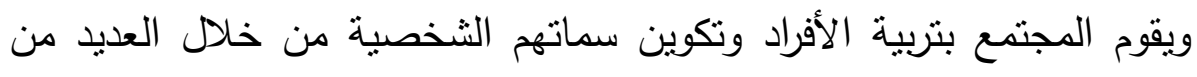

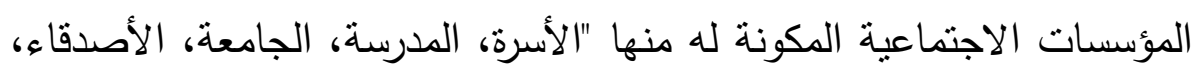

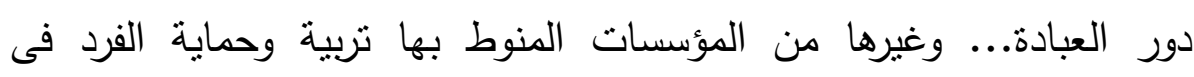

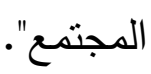

وتعد الأسرة أهم المؤسسات الاجتماعية التى تربى وتتشئ الأبناء على

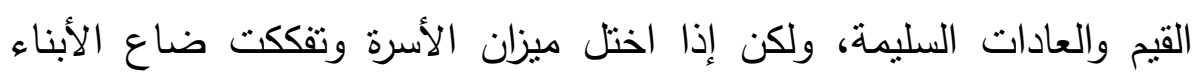

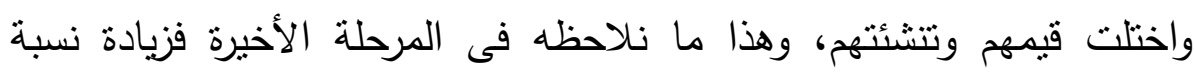

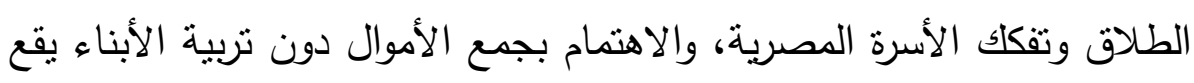
بالسلب عليهم ويخل بتكوينهم النفسى. إن تفكل الأسرة وعدم قيامها بالدور

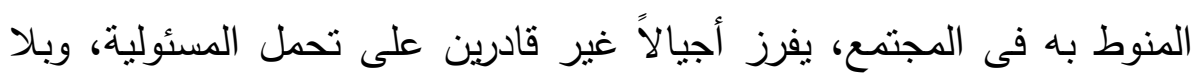

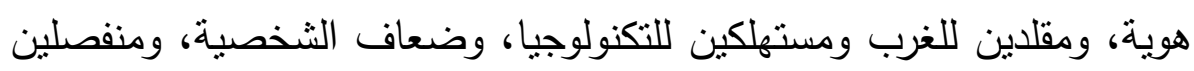
عن مجتمعهم، ومن ثم يكونون فريسة سهلة للجماعات المنطرفة.

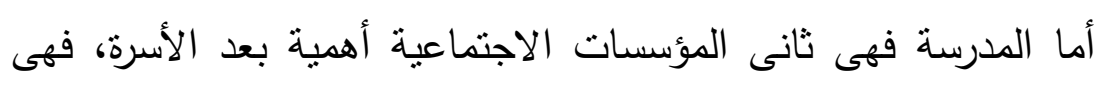

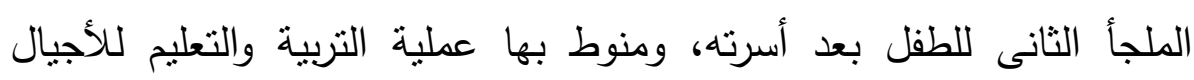

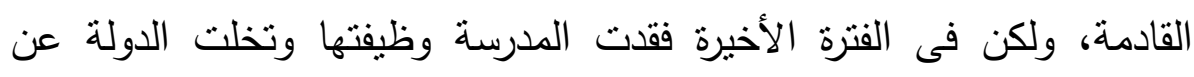


دعمها والرقابة عليها، وتتوعت المؤسسات التعليمية وتحكم رأس المال فيها

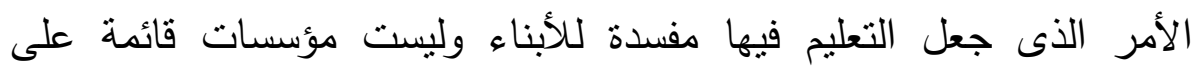
تربيتهم وتعليمه، فالتعليم الدولى واللغات والخاص والتجريبى والحكومى لإنى

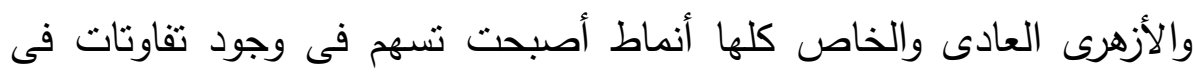
القدرة على تعليم الأبناء، ومن ثم ساعدت تللك المؤسسات التعليمية على إفراز

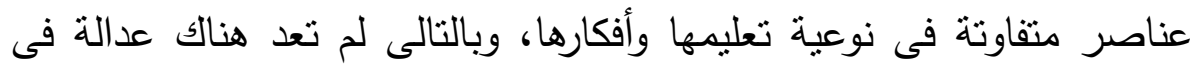

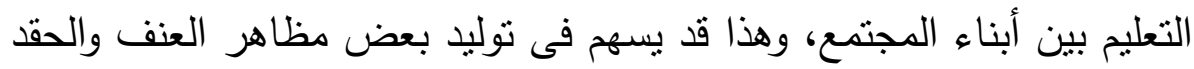
بين بعض الأقراد فى المجتمع. والجامعة فى مصر من أهم المؤسسات التربوية والتعليمية أيضا، المنوط بها تتمية الثقافة الفكرية والعقلية للطلاب وإكسابهم المهارات المختلفة التى التى

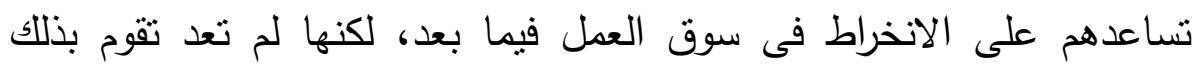

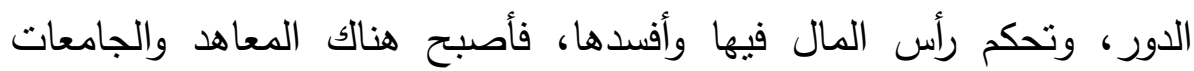

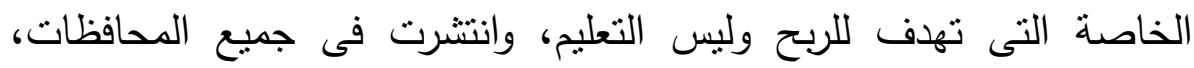
وغابت الرقابة على مناهجها وطرق التدريس بها، مما سهل تكوين أفكار مختلفة وتوجهات سياسية متعددة، وبثها من خلال منابر الجامعات المختلفة

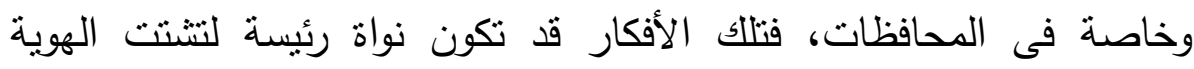

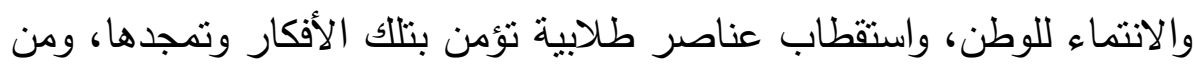
ثم تكون بداية للتتظيمات المتطرفة التى لا تتتمى للاولة وتستعديها.

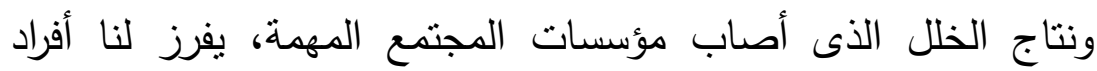
يشعرون بضعف وفساد المجتمع ومؤسساته، ويمنلكهم شعور بعدم الرغبة والبقاء فيه، ومن ثم يحاولون الهجرة لبلد آخر ، أو يتجهون إلى تهميش أنفسهر وفئه وتكوين ثقافة مختلفة عن الثقافة السائدة فى المجتمع، وهذه الثقافات قد تكون 
موجهة ولها أفكار سياسية أو دينية وقد تكون عشوائية مستوحاة من الغرب،

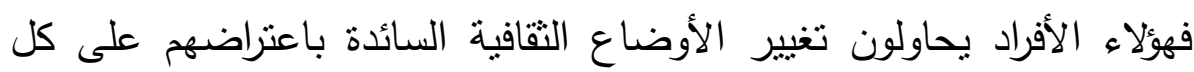

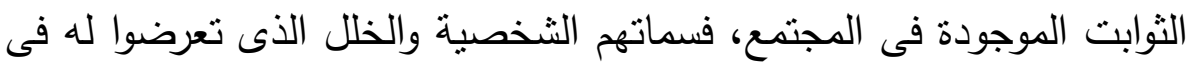

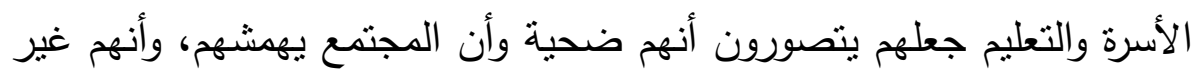

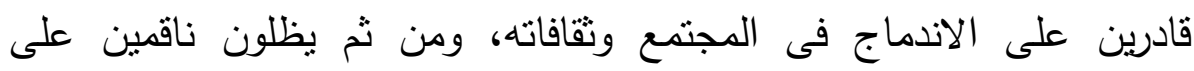
المجتمع ولديهم الرغبة فى الانتقام منه. كل هذا ينتج عن غياب الدور الحقيقى لمؤسسات الدولة التى تعمل على نشر الثقافة الحقيقية، وهى مؤسسات موازية

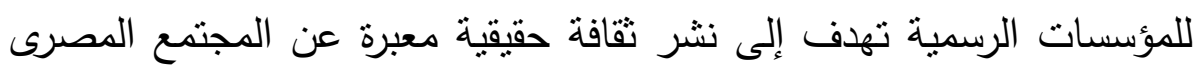
وتقتح الآفاق أمام التفكير والإبداع. وإذا أضفنا أن فثل التعليم فى التأصل والتجدر في شیى شخصية الفرد

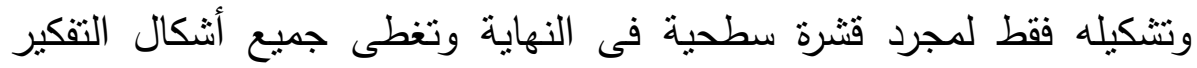
السقيمة والسائدة القائمة على الحفظ والتلقين وقتل الإبداع والفكر ، نستطيع فهم الأسباب الكامنة وراء تفشى التعاطى الخرافى والغيبى مع ظواهر هذا لهاء الواقع. هذا بخلاف ما يكمن فى الحياة من ظواهر وتسلط وقهر (السادومازوشية)

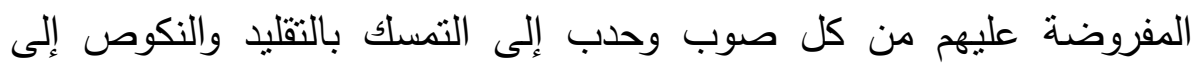

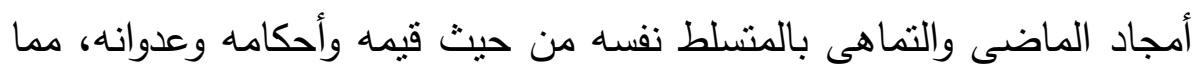

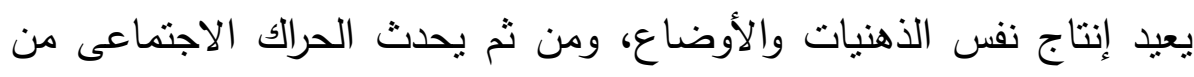

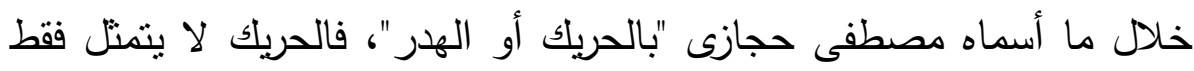

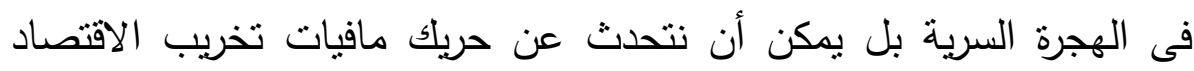

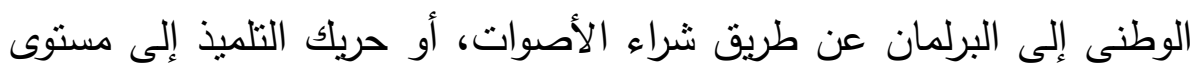

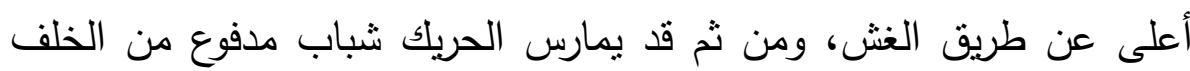


بمرارة الفقر ومجرور من الأمام بوعد جنة الاستشهاد الموهوم ومحاصر سياسيا ومعرفيا من أعلى وأسفل(؟).

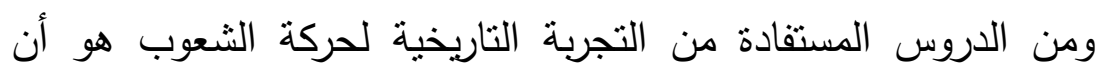

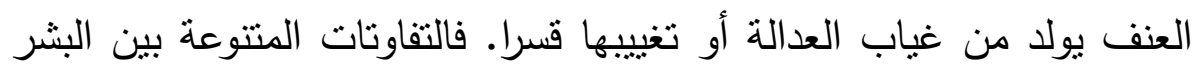
تتشأ من اختلالات فى المنظومة المجتمعية بمستوياتها الاقتصادية والاجتماعية

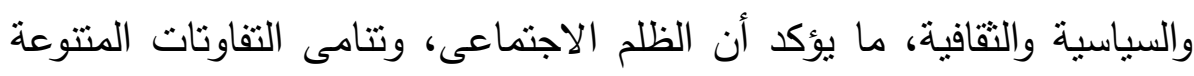
هما وقود العنف وتبنى أيديولوجيته (V).

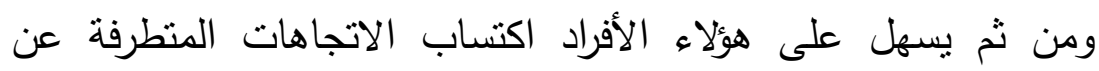
طريق عمليات التدريب الاجتماعى التى تغرس فيها قيمة تقديس التطرف بتأكيد

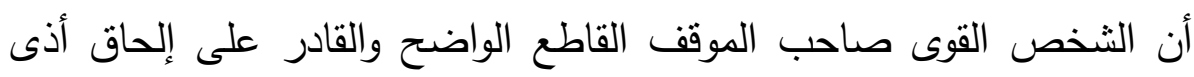

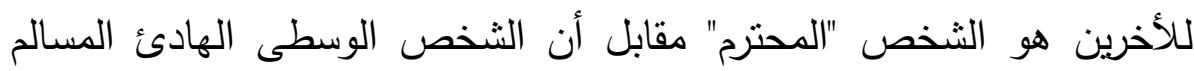

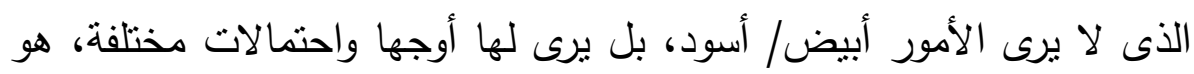

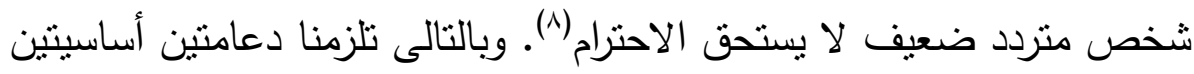

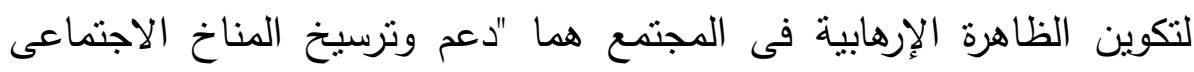
الفكرى الأصولى، وتوفير التمويل اللازم للتجنيد والتنديب والتسليح والإعاثنة إلى آخره"، ومن ثم يدفعنا هذا للتساؤل حول تمويل تلك التنظيمات الإرهابية

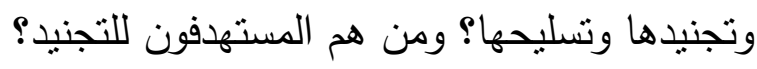

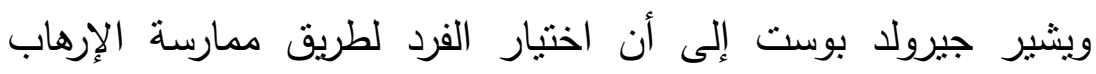
يضرب بجذوره فى تتشئتهم الاجتماعية المبكرة التى غرست فيهم البذور الفكرية

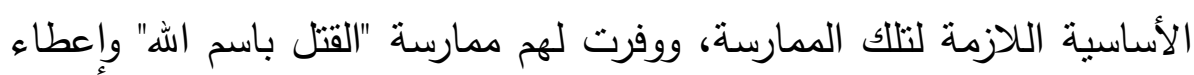
أعمالهم مغزى مقدسا من قبل رجل الدين المنطرف، سواء كان آية الله، أو أو أولاء

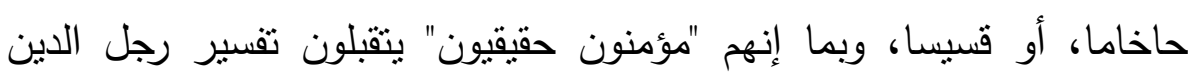


المتطرف للكتب المقدسة بدون جدال، فيقدمن على التضحية بأنفسهم وهم

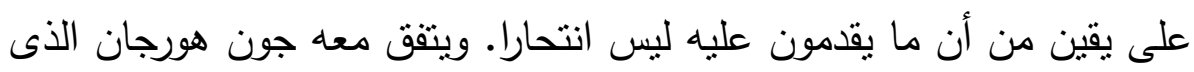

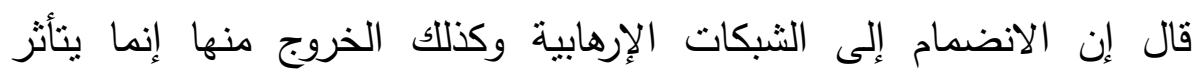
بالظروف المحيطة بالفرد بأكثر من نأثره بملامح شخصيته الإنهابة وكان. فالمؤسسات المسئولة عن نشر الثقافة الحقيقية عن المفاهيم وثوابتها

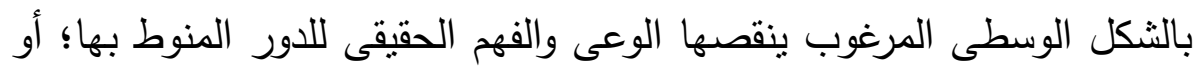

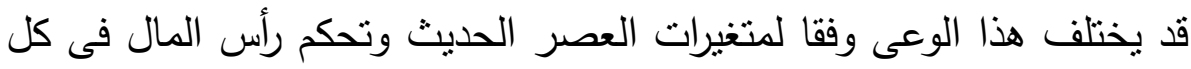
عناصره وسياقاته المختلفة، ومن ثم ضعف الدور الذى تقوم به مؤسسات الدولة المسئولة عن التوعية الثقافية العميقة التى تعمل من أجل تدعيم الهوية المصرية، وإن ارتبط معظمها بشخص المسئول عنها وليس وفقا لاستراتيجية

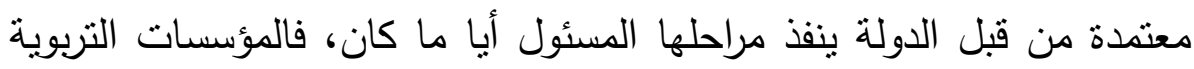
والدينية والإعلامية عليها الكثير من الأدوار المنوط بها لتحقيق حماية الأبناء

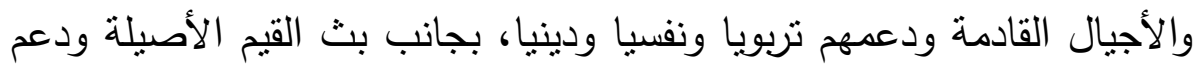

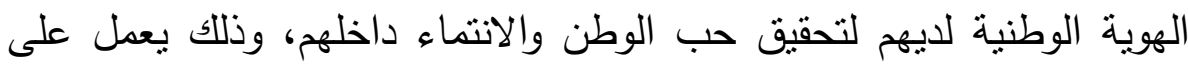

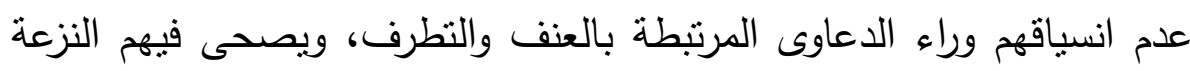

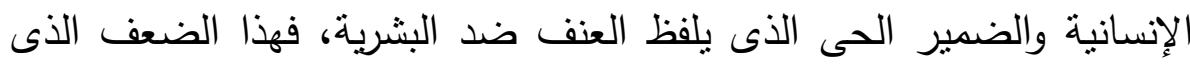

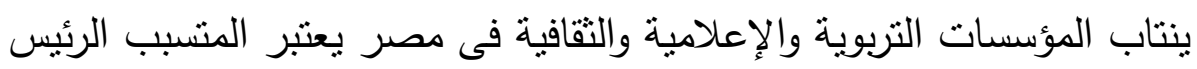
فى استقطاب الثباب وانضمامهم لهذه الجماعات الإرهابية.

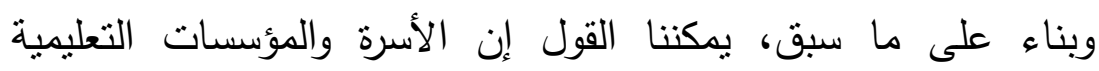

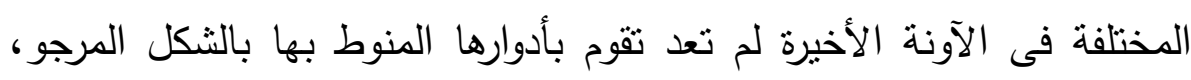

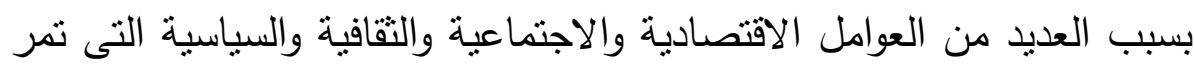


بها، ومن ثم يؤثز ذلك فى جيل الثباب بصفة خاصة، ويصبحون الفئة الأكثر استعدادا للتأثر بالفكر الإرهابى.

\section{ثالثا: الإرهاب بين الدين واللادين}

إن مفهوم الإرهاب فى الوقت الراهن غير متفق عليه لاختلاف الهذف والنظرة

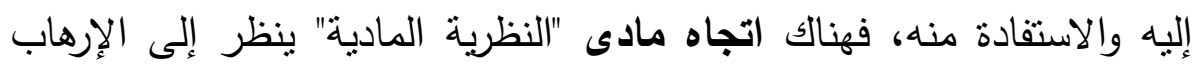

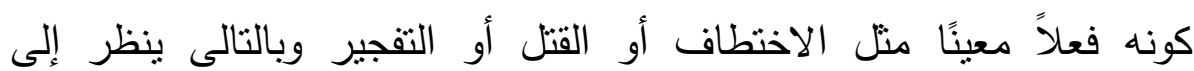

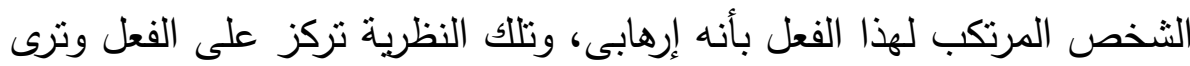
أن الإرهاب فى تطور مستمر لذا لا يمكن التتبؤ بالفعل مستقبلا، كما أنها

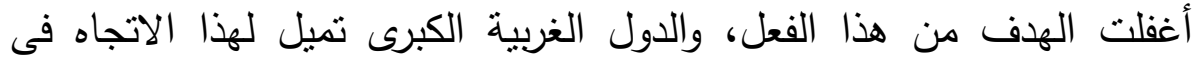
نظرتها إلى الإرهاب. أما الاتجاه الموضوعى "النظرية الموضوعية" فهو يميل

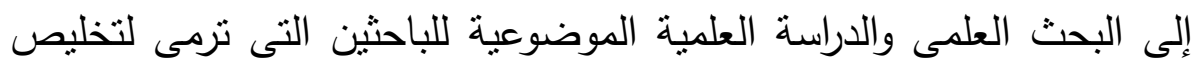

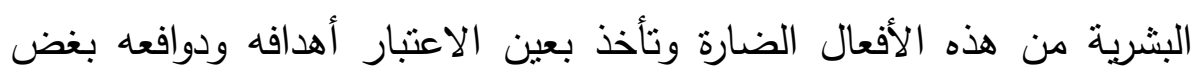
النظر عن أساليبه وأنشكاله(·'). لذا ربط الإعلام الدولى العمليات الإرهابية التى تحدث فى أى دولة التى

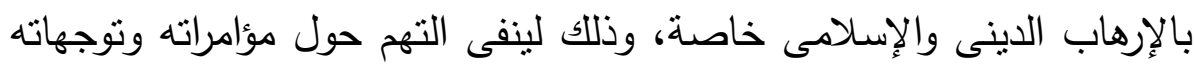
السياسية لتقتيت دول بعينها، ويظل الإعلام الغربى يركز على هذا الرابط لكى واليى

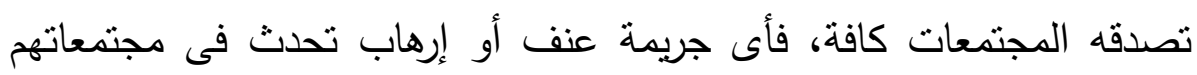

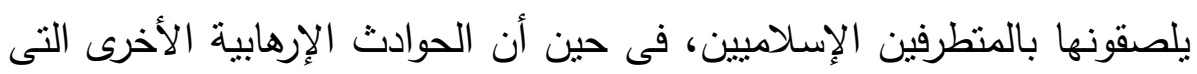

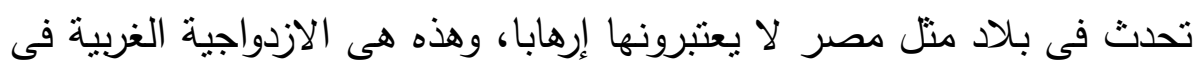

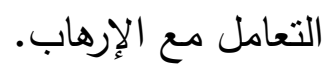


فالإعلام الغربى يفسر الأمور فى ظل سياق ثقافى ومجتمعى يساند ما

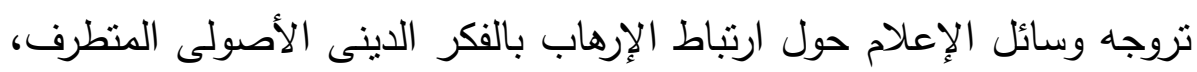

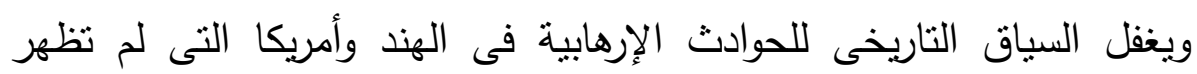

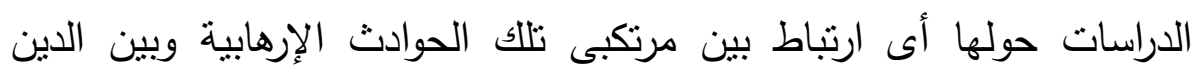

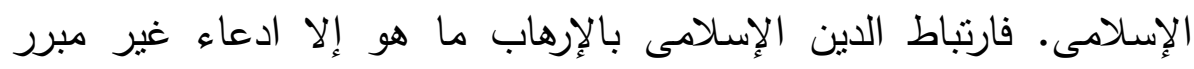

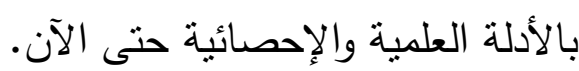

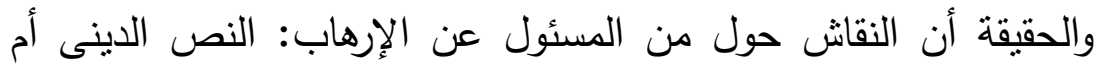
السياق الاجتماعى والسياسى المحيط هو نقاش ارتبط بالتحولات التى أصابت الابت التهن التيارات المتطرفة فى نصف القرن الأخير ، فدوافع الإرهاب طوال العقود الثنالثة

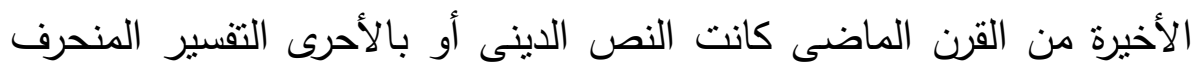

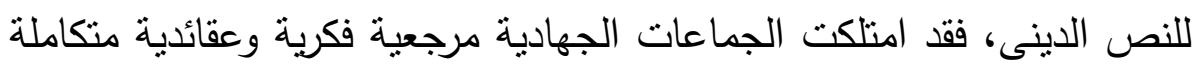

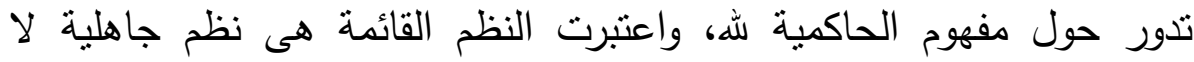

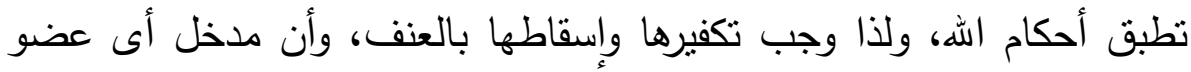
للانضمام إلى التظظيمات الجهادية الكبرى كان يبدأ بالإيمان بمرجعية عقائدية

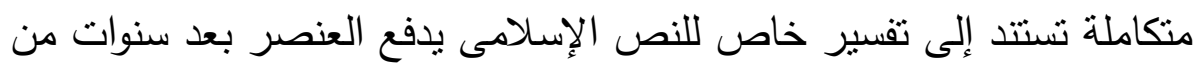

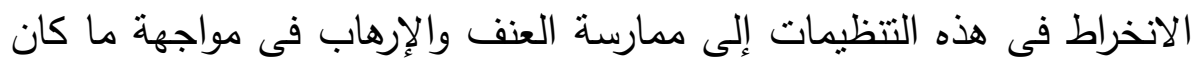

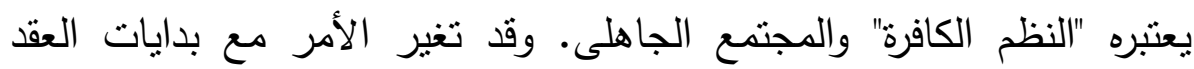

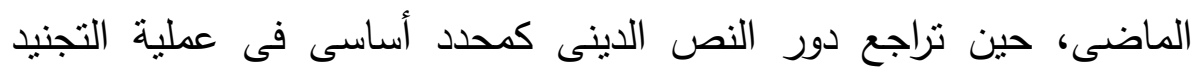

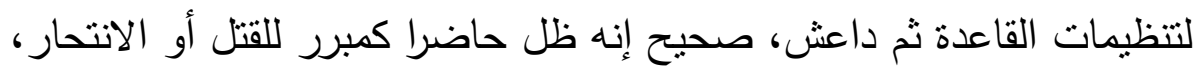
ولكن من يصنع الكراهية والإرهاب وتكفير الدخالف لم يعد أساسا تفسيرا منحرفا للنص الدينى يقضى التكفيرى سنوات لدراسته، مثلما فعل جهاديو القرن الماضى؛ إنما هو واقع طائفى فى العراق أثنعر قطاعا واسعا من السنة لإسنه 
بالاضطهاد والتهميش، أو مظالم سياسية وطائفية وجرائم حرب ارتكبها النظام

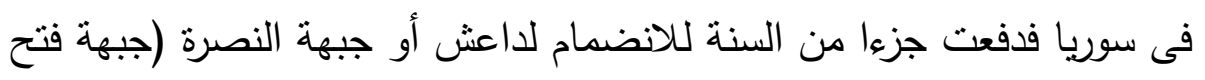

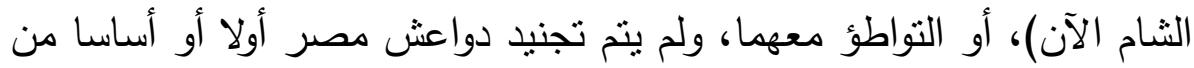

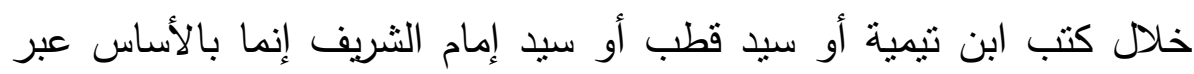

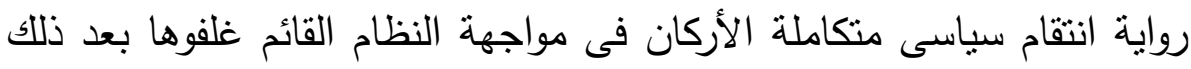

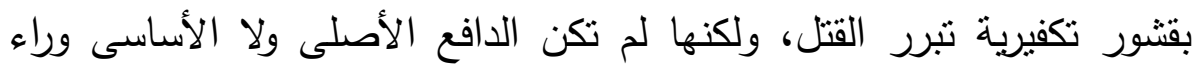

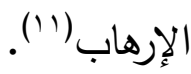

فتطور مفهوم الإرهاب الجديد وخاصة فى ظل سياق مجتمعى ونقافى مختلف، يجعله لا يمت لصلة بالدين الإسلامى الذى يدعو إلى الدحبة والتسامح والمساواة، والذى انتشر وما زال ينتشر بالعقل وليس بالسيف، فهذا

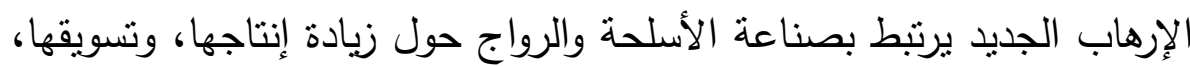

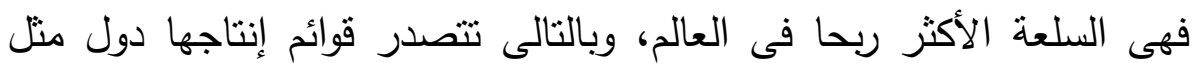
"الولايات المتحدة الإمريكية، روسيا، فرنسا، بريطانيا، ألمانبا، هولندا"، وتستأثر

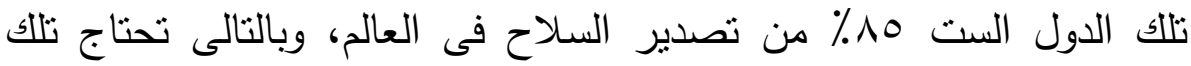

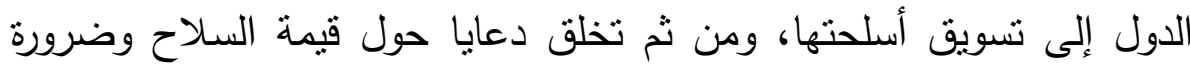
الاحتفاظ به، هذا بخلاف المؤامرات التىى تدبرها تلك الدول لتوريط مجتمعات

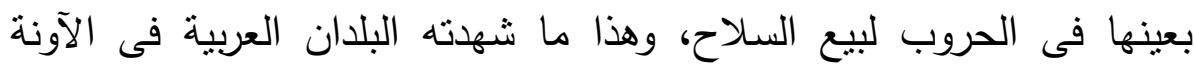

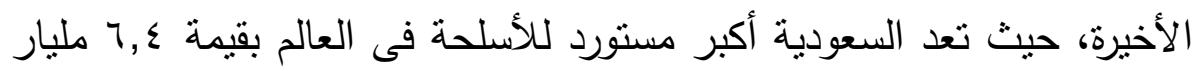

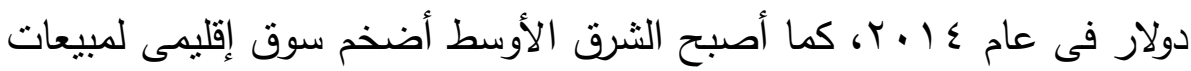
الأسلحة ويتوقع أن تبلغ وارداته منها نحو ، ل11 مليارات الدولارات خلال

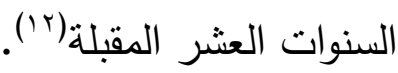


وهناك من يصر على مناقتنة الإرهاب الجديد ولصقه بإرهاب المرجعيات

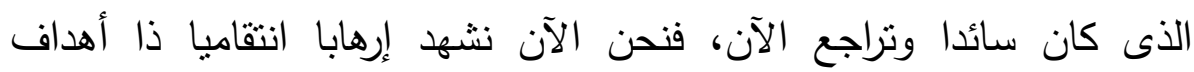
سياسية، مرتبط بترويج الأسلحة وتدمير البلاد.

\section{رابعا: الإرهاب بين الجبتهع الواقعى والافتراضى البهى}

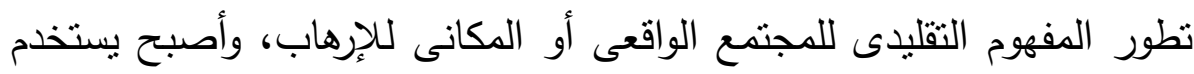

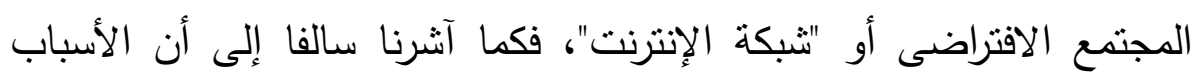

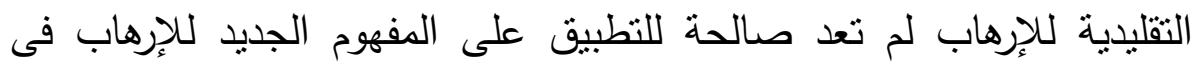

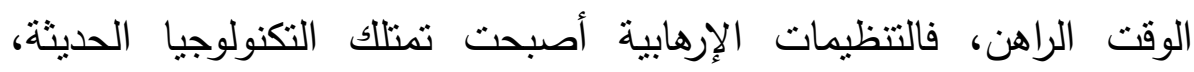
واستخدمت شبكة الإنترنت بكل قوة فى حثد وجذب الأفراد للانضمام إليها عبر الإرهابه النيه

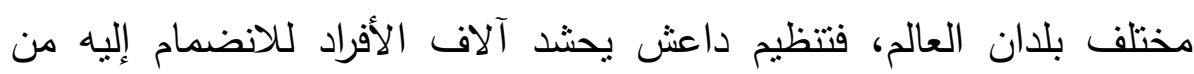
خلال الإنترنت، فلديه جيش جبار دوره الرئيس هو بث الأفكار عبر الإنترنت، والتواصل مع الأفراد لإقناعهم بأهداف التنظيم وأفكاره.

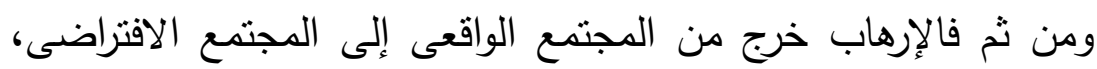

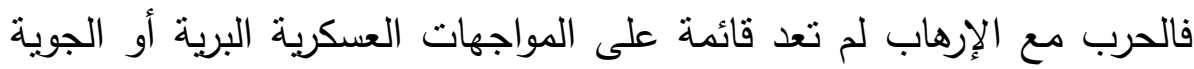

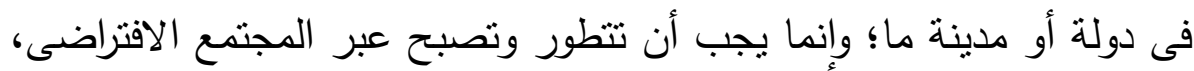
ومحاربة الفكر بالفكر، ومتابعة المواقع الإكترونية المختلفة النى تستخدمها

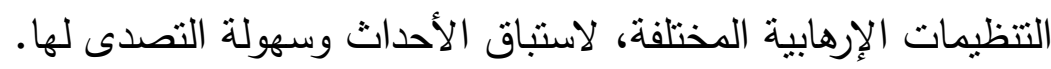

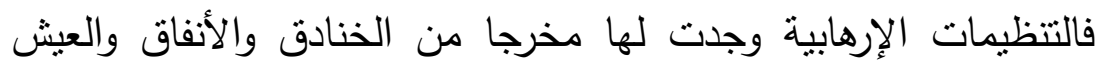

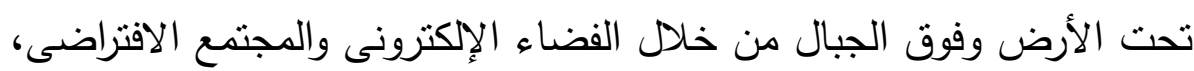

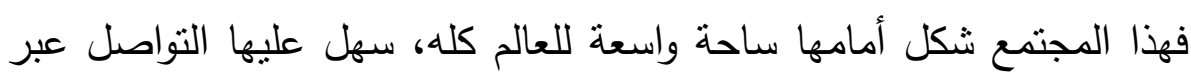
جميع دول العالم، ومن ثم أصبح العالم كله أمامها تمارس فيه المأه الأعمال 
الإرهابية والتفجيرات بدون رقابة أو سيطرة، كما سهل عليها التعرف على معلومات دقيقة عن كل مكان وكل فرد فى العالم، ومن ثم فثنبكة الإنترنت

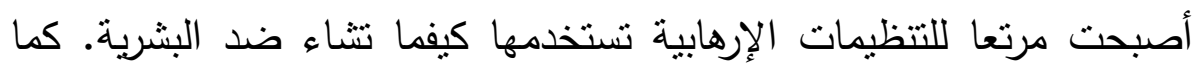
سهل عليها التواصل مع التنظيمات الأخرى، والنظم المخابراتية لثراء الأسلحة

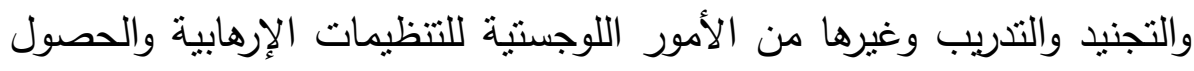
على الدعم المادى والمعنوى.

وتستخدم هذه التقنيات بفعالية ريما أكبر من فعالية استخدام الدول

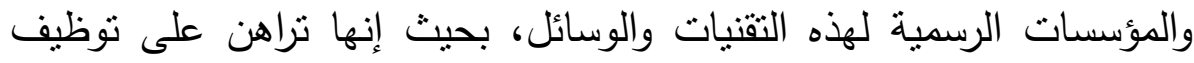

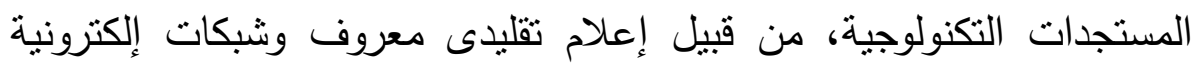
فائقة الدقة، إن لم يكن لترويع وشل حركة الأعداء، فعلى الأقل لإحراج

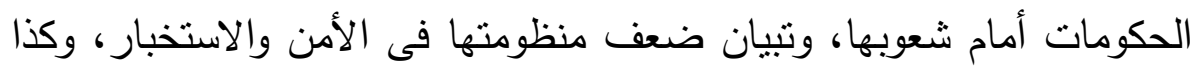
قدرتها على المواجهة والرد (r'). هذا بجانب الإعلام، فدراسات علم النفس الإعلامى تؤكد أن رواج سلعة معينة لا يتوقف على مجرد الإعلان عن وجودها وعرض مزاياها، بل إن إن إعل

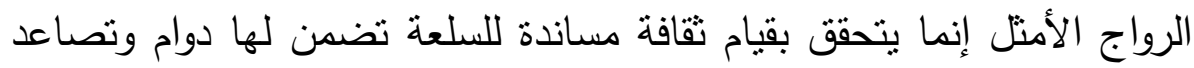
الطلب عليها. ويتطلب خلق مثل هذه النقافة نتكيلا لخريطة الوعى بما تتضمنه من معايير وقيم واتجاهات، بحيث يصبح الطلب على تلك السلعة

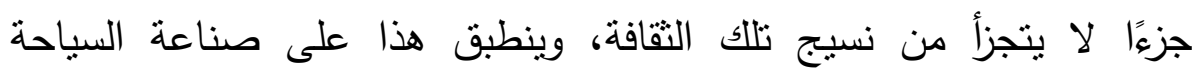
والأسلحة والإرهاب. ومن ثم سهل المجتمع الافتراضى عملية الرواج لصناعة فئل الإرهاب، واستخدام القوة والعنف، وجذب المنطرفين من مختلف الجنسيات والأعمار لهذه الصناعة. والخدماب. 
وخلاصة كل ما سبق، إن العلاقات والارتباطات الجدلية التى حاولت

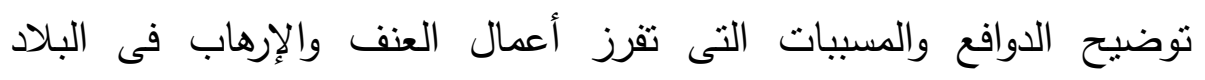

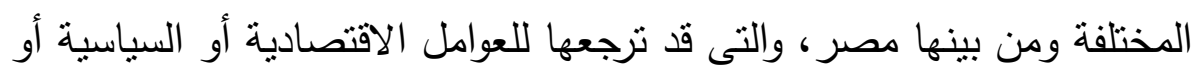

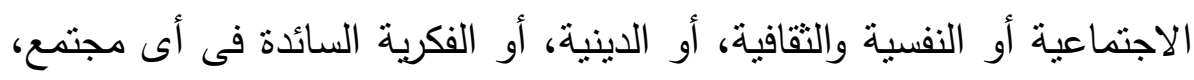

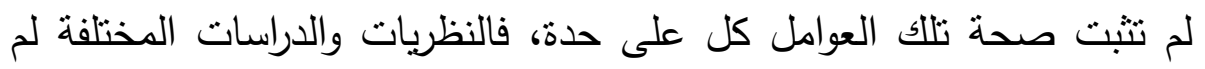

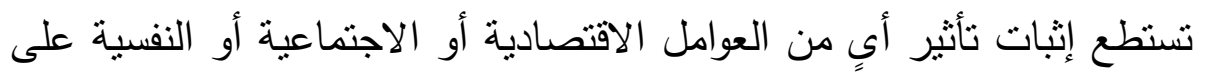

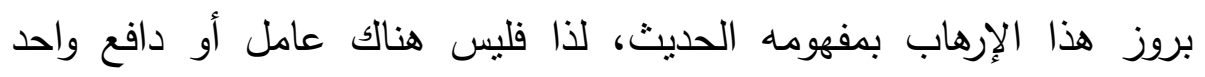

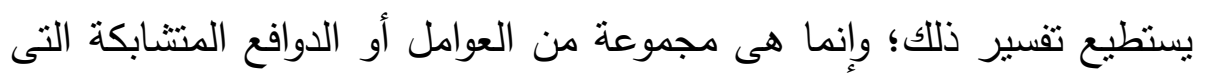

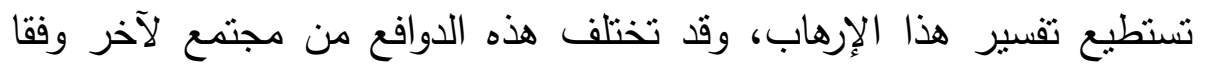

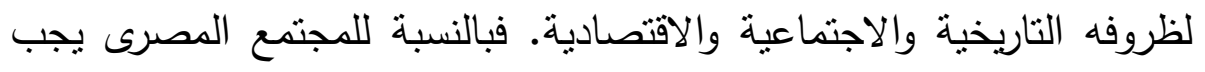

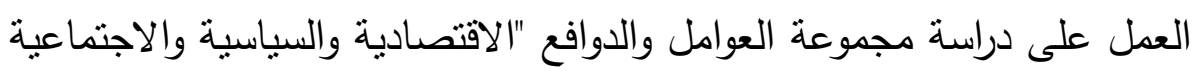

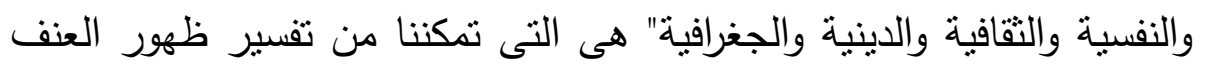
والإرهاب الجديد داخل أراضيها، ولا يمكن إغفال أى دافع منهم، كما لا يمكننا

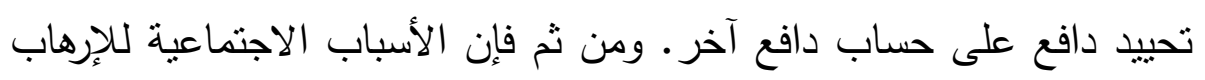

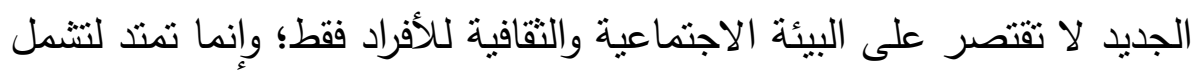

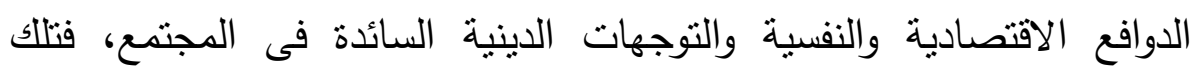
الدوافع تنشكل بيئة حاضنة للإرهاب وتستهدف الثباب بشكل أساسى.

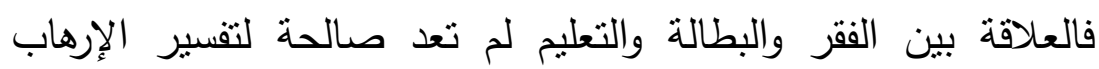

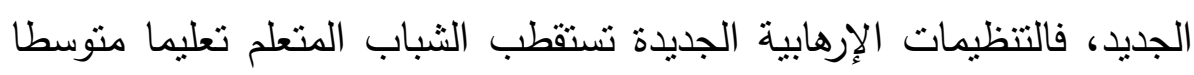
أو جامعيا، كما أصبح الانضمام لمنل هذه التتظيمات بمثابة العمل المربح للفرد

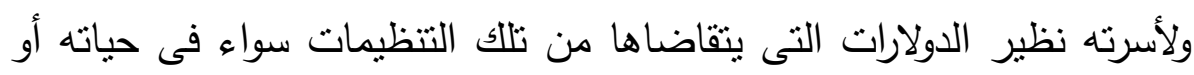
بعد استشهاده، كما لم تعد العلاقة بين الإرهاب والدين الإسلامى صالحة لإنة 
للتفسير، فكلها دعاوى تروجها وسائل الإعلام الغربية لكى تبرر أعمالها وخططها التدميرية داخل بلدان الشرق الأوسط، ومن ثم فإن التفسيرات الصالحة للإرهاب الجديد تمثلت فى ضعف المؤسسات التربوية والثقافية والدينية والإعلامية وعدم قيامها بالأدوار المنوط بها على الوجه الصحيح، ومن ثم تقرز

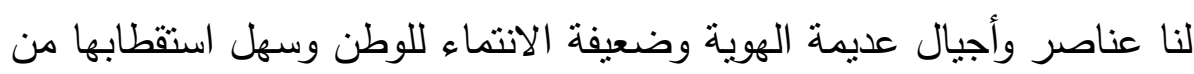
قبل هذه التنظيمات الإرهابية.

كما تراجع المجتمع الواقعى كمكان لساحة المعارك الإرهابية، وارتبط الإرهابة

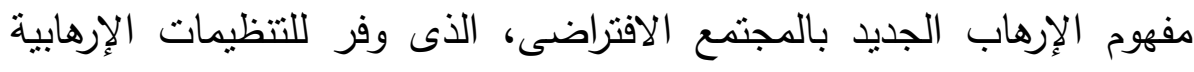

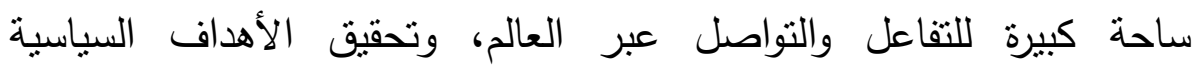

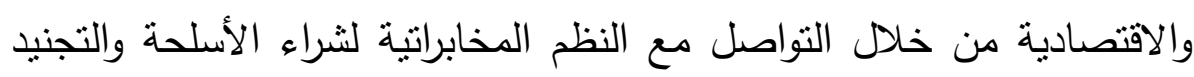

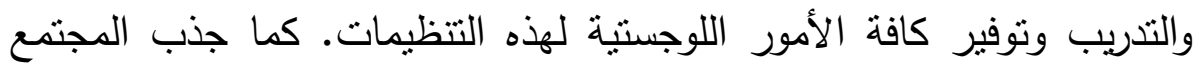

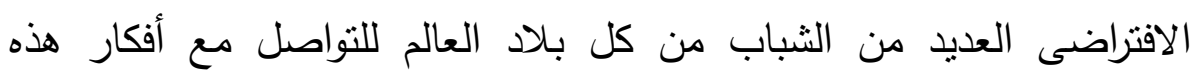

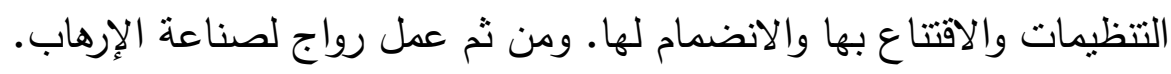

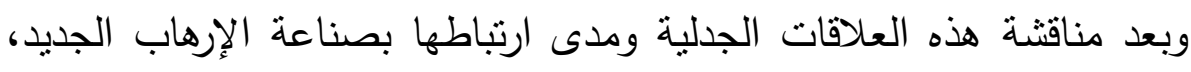

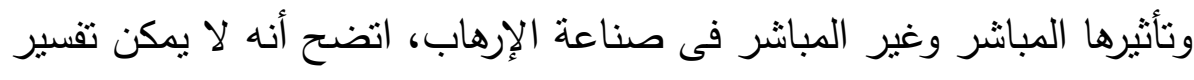

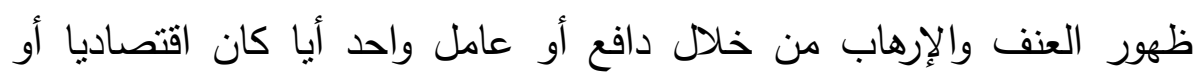
اجتماعيا أو نقافيا، فالمجتمع المصرى يتميز بخصوصية نقافية دافية وتاريخية،

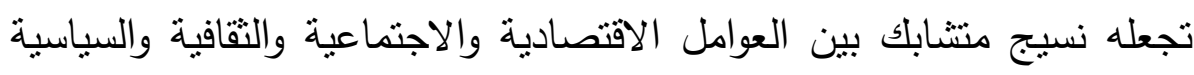

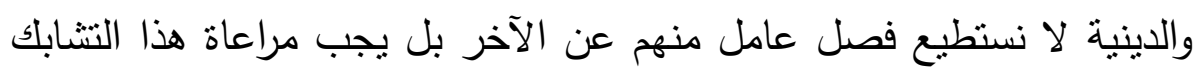
عند التفسير والتحليل. وبالتالى فالثباب المصرى يعانى من ضعف البنية الاجتماعية والثقافية

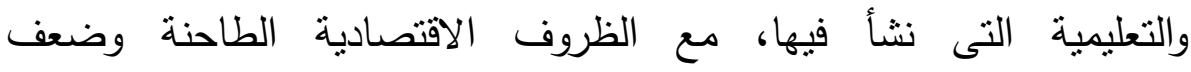


الديمقراطية، وانتشار المحسوبية والتسيب والفساد، والفوضى الإعلامية، وتعدد

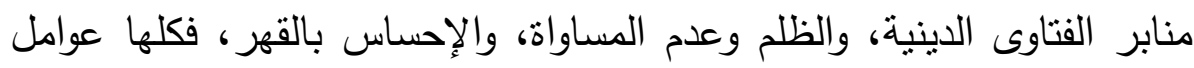

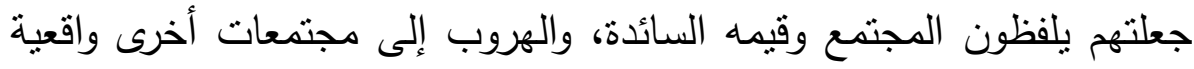

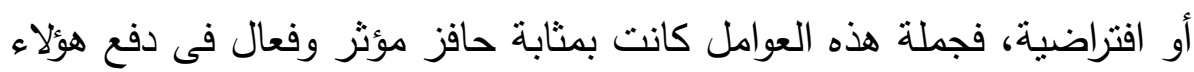

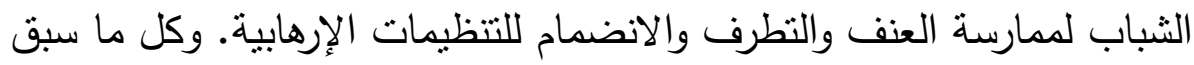

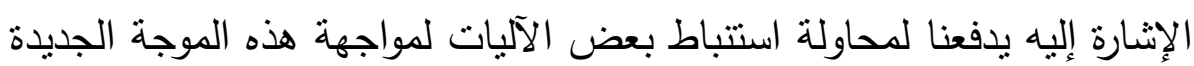

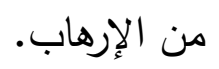

\section{خاهسا: آليات هكافهة الإرهاب البديد}

تصاعدت وتيرة الأعمال الإرهابية فى مصر خلال الفترة الراهنة، وأخذت منحى

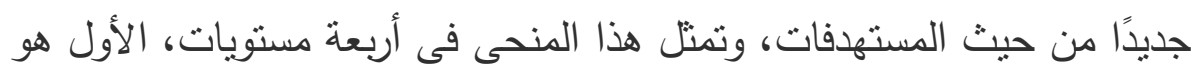

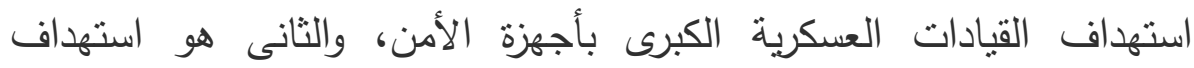

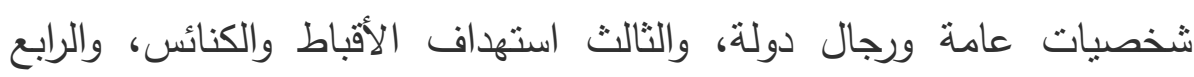
استهداف المسلمين والمساجد. وتعد المستهدفات السابقة هى أهداف جديدة ولهات تضاف لمستهدفات عدة سيطرت على أداء التظظيمات الإرهابية خلال أعوام

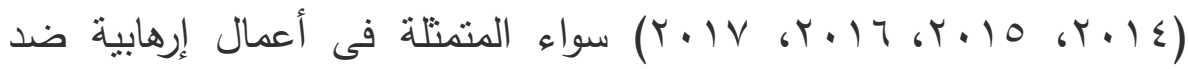
البنية الأساسية للاولة باستهداف مرافق عامة (كهرباء- خطوط غاز - وسائل مواصلات)، أو استهداف قوات الأمن (جيش- شرطة)، مع استمرار الأعمال الإرهابية من قبل (تظظيم بيت المقس وداعش) ضد قوات الجيش فى سيناء.

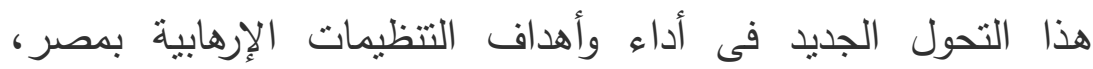

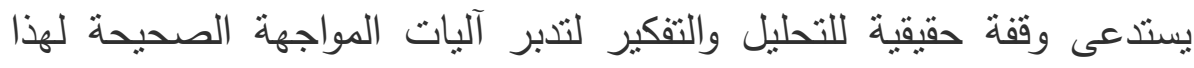

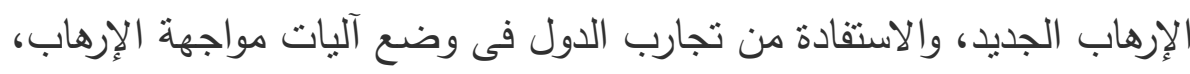




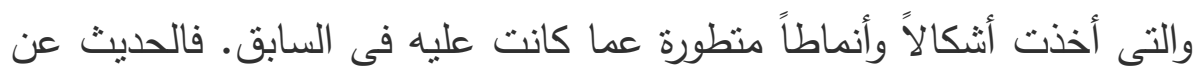

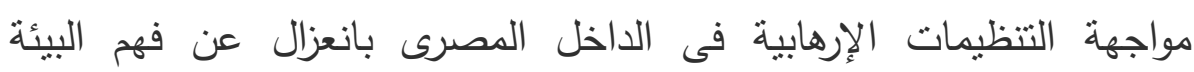

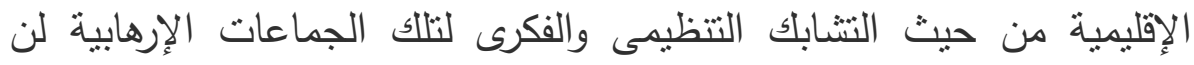

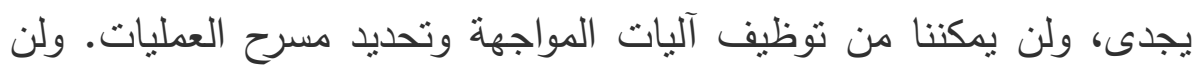
يمكننا من ربط الخطوط العريضة للإرهاب وما ورائه من أهداف، والدول

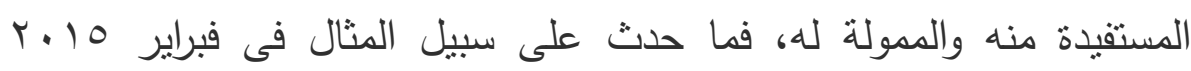
عندما قامت القوات الجوية الدصرية بضرب أهداف فى مدينة "درنة" اللايية رداً

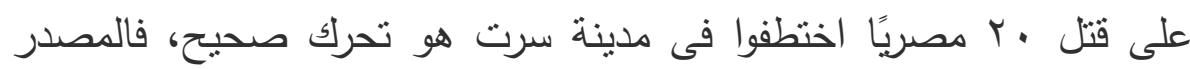
يقع فى مدينة "درنة" بالرغم من عدم وقوع جريمة الاختطاف والقتل فيها، وهذا

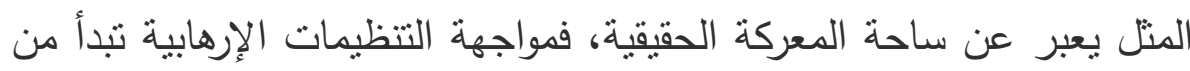

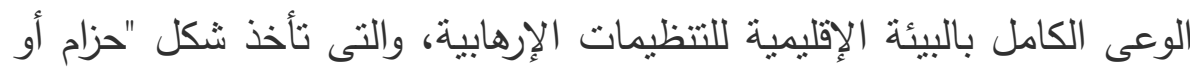

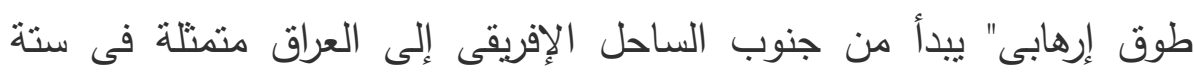

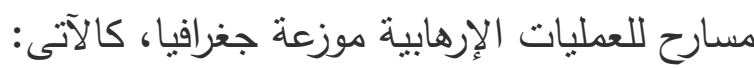
1 - بتظيم القاعدة فى أفغانستان وباكستان.

r- فتح الثام "جبهة النصرة سابقا"، وتنظيم داعش فئ سوريا والعراق. r- تتظيم القاعدة فى اليمن وامتداده فى منطقة القرن الإفريقى، والمحاكم

$$
\text { الإسلامية والتتظيمات الجهادية فى الصومال. }
$$

ع- ولاية سيناء "تنظيم بيت المقس"، بجانب تتظيمات إرهابية سائلة نأخذ

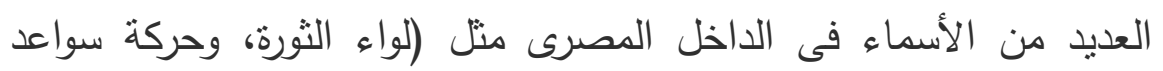

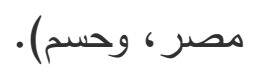

ه- تتظيم أنصار الثريعة، والمرابطون، و "داعش" فى ليبيا، وامتداد تتظيم القاعدة فى تونس والمغرب والجزائر . 
צ- تتظيم بوكو حرام بنيجيريا والمنتاخل مع الوضع فى ليبيا ومالى وتثناد،

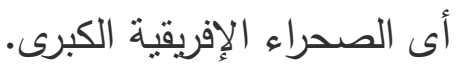

وقد شكلت هذه التنظيمات الإرهابية تحالفين إقليمين (تتظيم القاعدة

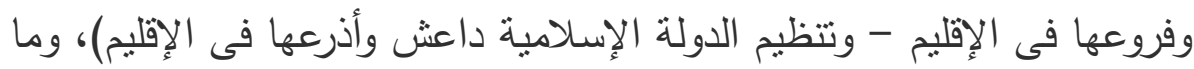
يميز هذه التحالفات هو سهولة انتقال الأفراد بينها، فبعض التنظيمات التهات التابعة

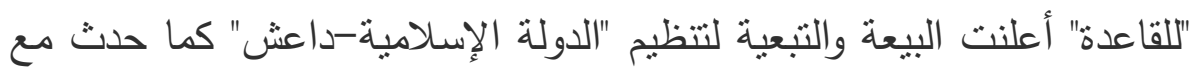
تتظيم بيت المقدس فى سيناء، فضلاً عن تميز هذه التنظيمات باستخدام

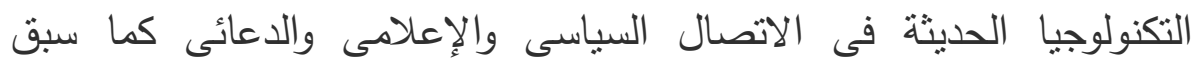

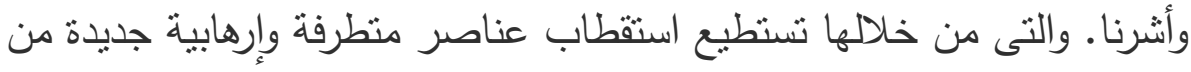

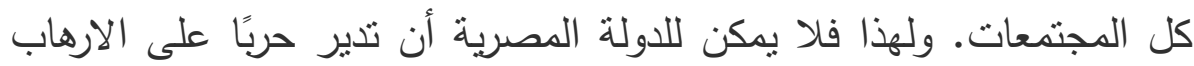
بشكل منفصل عن البيئة الإقليمية (؛) (1). وبناء على ما سبق، فإنه لمواجهة الإرهاب الجديد فى مصر، يمكننا

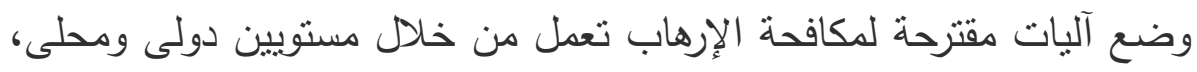
وعلى الدولة المصرية العمل فى كلا المستويين بالتوازى، وذلك كالآتى:

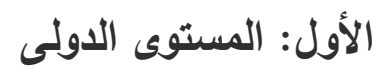

بما أن الإرهاب الجديد عابر للحدود ويستخدم التكنولوجيا الحديثة لذا فالدولة المصرية بحاجة إلى التعاون الإقليمى والدولى لتبادل المعلومات، ومراقبة

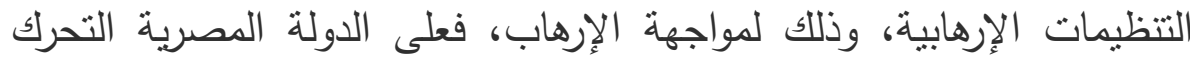

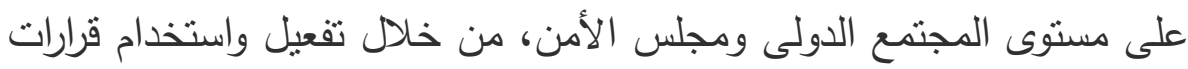
مجلس الأمن فى مواجهة الإرهاب الجديد، حيث صدرت العديد من القرارات من

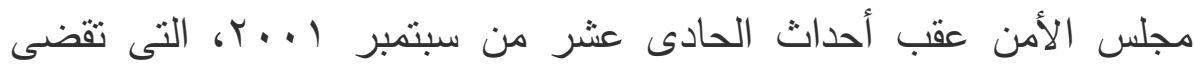

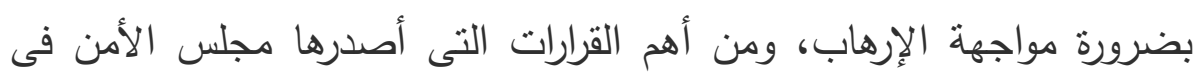


هذا الثأن هما قرارى ش؟r| "الذى أكد على ضرورة عدم الاقتصار على

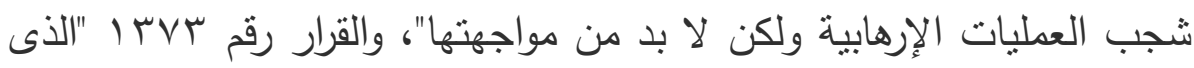

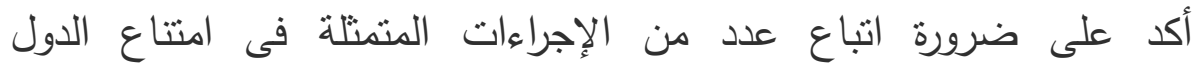

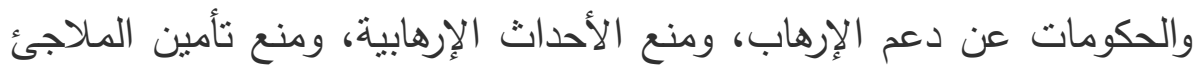

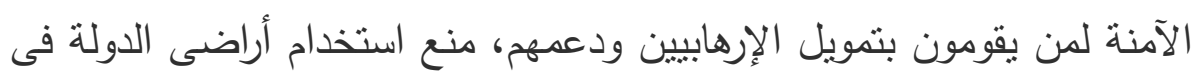
الإرهاب الدولى، مساعدة الدول فى عمليات التحقيق فى الجرائم والعمليات الاتحني

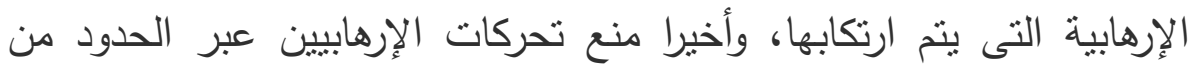

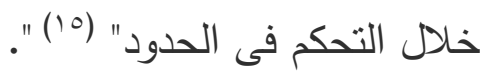
هذا بجانب العمل على صياغة وثيقة وطنية لمهددات الأمن القومى تحدد التهديدات الحالية والمقبلة الداخلية والخارجية، وتضع استراتيجيات وخطط

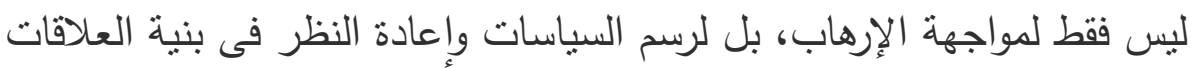
والتحالفات المصرية على المستويين الإقليمى والدولى.

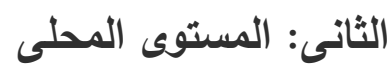
ينت ذللك من خلال عدة عناصر هى:

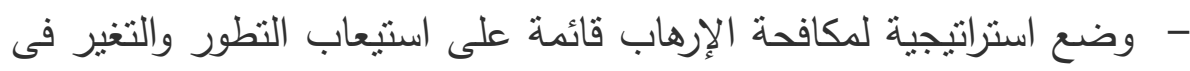

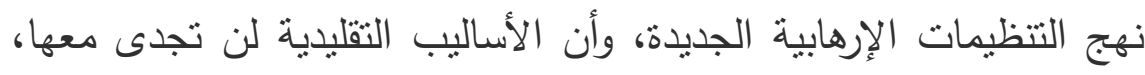

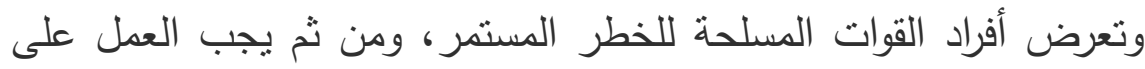

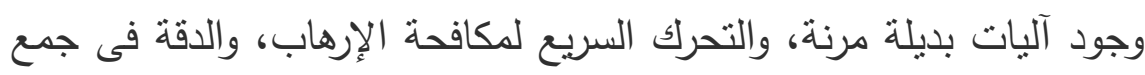

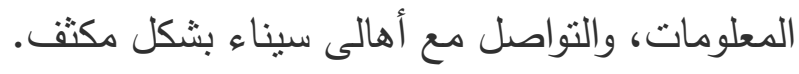

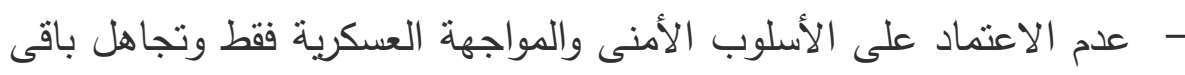
مسارات المواجهة، فذللك يؤدى إلى تفاقم الوضع ويضعف من الآنس آليات الحل. 
- العمل على ضرب بنية التنظيم المكونة من "التسليح، المال، الاتصالات"

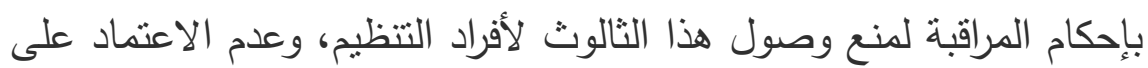
مواجهة أفراد التنظيم البشرية. - - إحكام المراقبة على قوات الأمن المفصولين والمحالين إلى المعاش خاصة

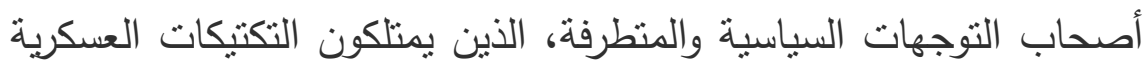
والتدريب، ويمدون الإرهابيين بالمعلومات والخطط.

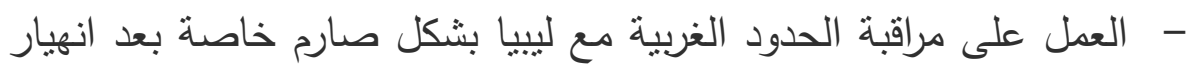
الدولة الليبية، والحدود الجنوبية، لمنع تهريب السلاح وتتقل أفراد التنظيمات

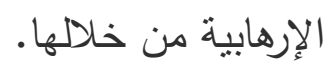
- الاستفادة من تجربة روسيا فى حربها مع الإرهاب، وتطويرها للابابات

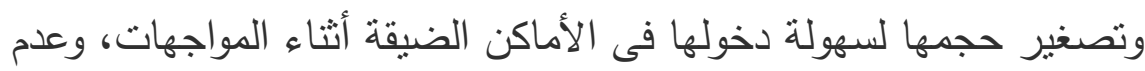

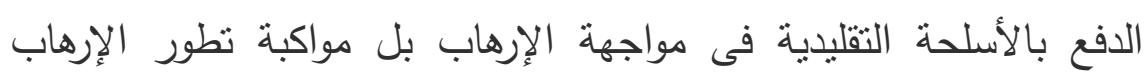

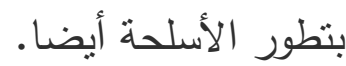

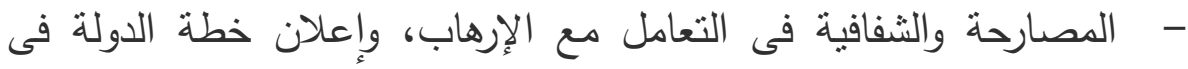
مواجهة الإرهاب الجديد عبر وسائل الإعلام المختلفة، ونقل الحقيقة للجماهير لتعبئة المواطنين فى دعم جهود الدولة المبذولة لمواجهة هذا

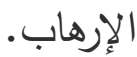
- الاهتمام بمراقبة وسائل الاتصال الحديثة وشبكات الإنترنت، التى تستخدمها

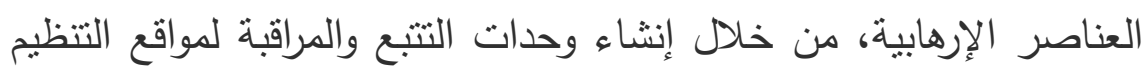
عبر الثبكة، والسرعة فى رصد اتصالاتهم وتحركاتهم ومواجهتها.

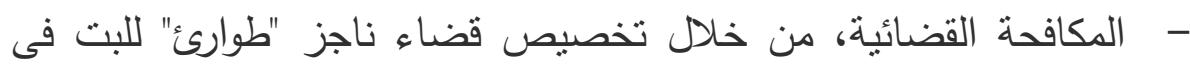
القضايا الإرهابية والعمل على سرعة تتفيذ الأحكام. 
- - وأخيرًا، المكافحة الفكرية والثقافية، وذلك من خلال تغيير مفاهيم وثوابت

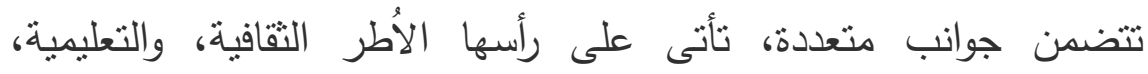

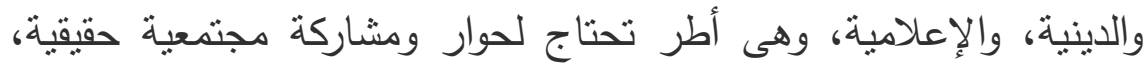

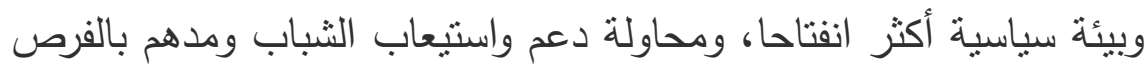

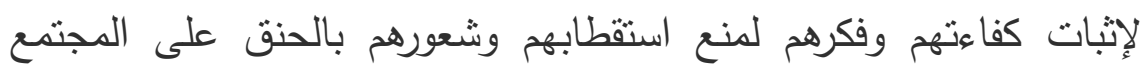
وتهميش أنفسهم. - المؤسسات التربوية "كالأسرة والمدرسة والجامعة" تحتاج لمزيد من التوجيه

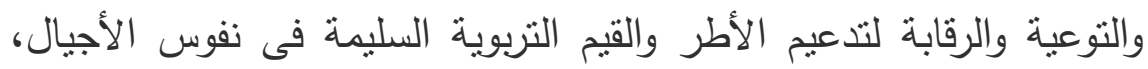

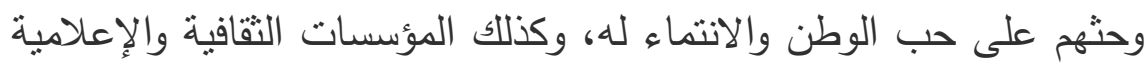
المختلفة عليها دور أساسى فى بناء الفكر الإيجابى وبثه بمختلف الوسائل والئل لكى يساهم فى بناء الثخصية السليمة التى تحبذ البناء وتتبذ الهام والعنف. - - هذا بجانب الدور المنوط به المؤسسات الرياضية فى دعم الثباب وتتمية

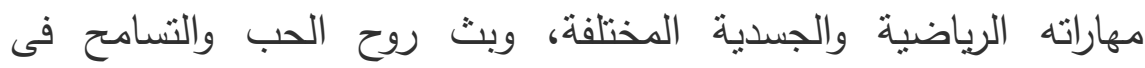
المسابقات الرياضية المختلفة. - تجفيف منابع الإرهاب من خلال دراسة الظروف الاجتماعية والثقافية

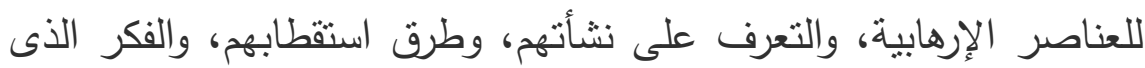
جذبهم للنطرف والإرهاب. - العمل على إنقاذ الأجيال الجديدة من الثباب من الثتعور بالتهميش والظلم

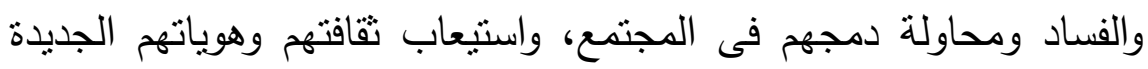
وعدم النفور منها، ودراسة احتياجاتهم العمرية وخصائصهم النفسية والتقافية والاجتماعية، لإعادة دمجهم فى المجتمع. 


\section{المراجع}

1- هويدا عدلى رومان، النظام العالمى وتمويل التتمية وظاهرة الإرهاب، المجلة الجنائية

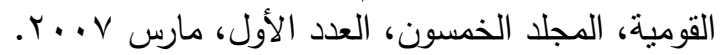

r- هيثم عبد السلام، مفهوم الإرهاب فى الثريعة الإسلامية، دار الكتب العلمية، بيروت، (

ץ- مجدى صبحى، عن العلاقة بين الاقتصاد والعنف، الديمقراطية، العدد VV، بوليو .

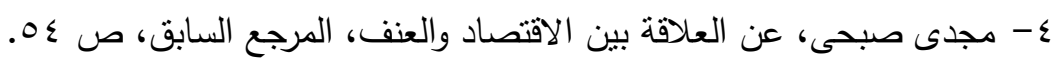

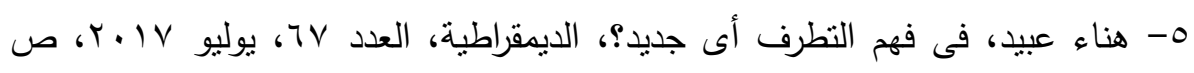
ص

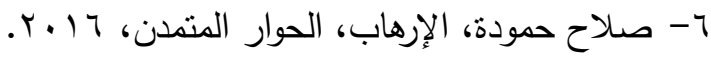

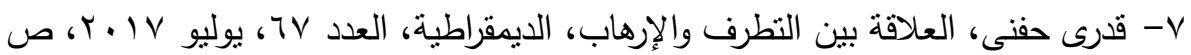

$$
\begin{aligned}
& \text { ^- قدرى حفنى، المرجع السابق، ص آـ. } \\
& \text { 9- قدرى حفنى، المرجع السابق، ص سז. } \\
& \text { • 1- هيثم عبد السلام، مرجع سابق، ص 7 ؟ـ. }
\end{aligned}
$$

11 - (1) عمرو الثوبكى، تحولات جماعات العنف وتحدى الإرهاب الجديد، الديمقراطية، العدد

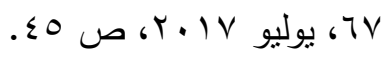

http://orient-news.net/ar/news show.

r إ- سماح عبد الصبور، الإرهاب الرقمى: أنماط استخدام الإرهاب الثبكى، مركز

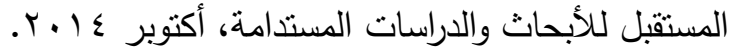

rا- أحمد كامل البحيرى، الحرب البطيئة لمواجهة الإرهاب، مركز الأهرام للدراسات

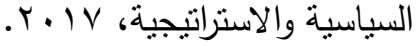

ع ا - أحمد كامل البحيرى، المرجع السابق. 


\section{SOCIAL CAUSES OF NEW TERRORISM}

\section{Hend Fouad}

Globalization has led to profound changes in the world; some of which were in favor of terrorism, and some others caused terrorism to go from local to global. Terrorism utilized communications development and easy information access. These changes and developments make us wonder about the method of these terrorist organizations, their origin, and the social causes of having extreme element joining such organizations, especially in the time being. Therefore, this study attempts to know the new strategies of terrorist organizations, the social causes of extremism and terrorism, and the significant mechanisms proposed to face it. 